OF THE

\title{
AMERICAN PHILOSOPHICAL SOCIETY,
}

\section{HRLD AT PHILADELPHiA, FOR PROHOTIVG USEFUL KVOWLEDGE.}

Vou. XXIII.

April, 1886.

No. 122.

MYRIAPODA MUSEI CANTABRIGENSIS, Mass.

Part I. Chilopoda.

By Fr. Meinert, Copenhagen.

(Read before the American Philosophical Society, October 2, 18S5.)

Several years since Mr. Alexander Agassiz, the director of the Museum of Comparative Zoölogy, Cambridge, Mass., through Dr. Hermann A. Hagen, offered to place in my hands the Myriapoda of that museum for examination and description. It was thought necessary at the same time to include the Myriapoda of the Museum of the University of Copenhagen, by which the work certainly gained as to completeness, but was on the other hand not a little delayed. When my report on the first part of the Myriapoda, the Chilopoda, was so far advanced that preparations for the press had to be commenced, there arose some difficulty as to a joint publication. I shall therefore begin with the Chilopoda of the Cambridge Museum, while the report upon that class in the Copenhagen Museum will appear in the "Naturhistorisk Tidsskrift," in which the greater part of my previous papers on the Myriapoda are to be found.

In the years 1866-1872, I treated both groups of Myriapoda in a series of essays, in all of which, in regard to the parts of the mouth, I accepted Savigny's explanation and used terms agreeing with it. Subsequently my studies of the different classes of the Arthropoda raised doubts in my mind as to the correctness and propriety of these explanations. Thus I was led to examine the foundation of the whole view of the subject, and when neither Savigny nor any of his school appeared to me to have taken the PROC. AMER. PHILOS. SOC. XXIII. 122. U. PRINTED DECEMbER 17, 1885. 
right starting point, I rejected the old explanation altogetherand based my views on a more general and, I hope, a more correct explanation of the parts of the mouth. I have, in later years, several times attempted to develop them and to apply them to these organs. At present, I shall limit myself to referring to the last of my essays "Caput Scolopendra," of which both a Danish and an English edition was published in 1883.* In this essay, by means of three plates, I have attempted to demonstrate the propriety of my new views with regard to the Chilopoda in general and Scolopendra in particular. In consequence of this also, several new terms were introduced; but Latzel and Haase had already, by their demonstration of the incorrectness of the explanation of the first and second pair of maxillæ, which Savigny and I also had supported, made some alteration necessary on this point. For the rest such alterations are only made when the old terms refer to an incorrect explanation. No reason was found for altering such terms as mandible for example, although formerly I reckoned these organs with the first segment or metamer, and now with the third metamer; for in the true Insects I consider the mandibles to be the third pair of the parts of the mouth. (That the mandibles of the Myriapoda and of the true Insects are not completely homologous is of no importance here).

I will now draw up the two series of terms; the old ones which I have used hitherto, and the new, which I proposed in my lately published "Caput Scolopendræ."

\section{OLD TERMS.}

Lamina cephalica.

Labrum.

Maxillæ primi paris.

Maxillæ secundi paris.

Pedes maxillares primi paris.

Mandibulæ.

Pedes maxillares secundi paris. Sternum (metameri quarti) cum pedibus prensoriis.

Coxæ (p. maxill.). Sternum (metameri quarti).

Dentes pedum maxillarium, se- Dentes prosternales, seu dentes cundi paris.
NEW TERMS.

Lamina cephalica (head-plate).

Labrum (upper lip).

Labium (under lip) p. p.

Labii processus interiores.

Maxillæ or palpi maxillares.

Mandibulæ.

* The complete title of the English edition is "Caput Scolopendra: The head of the Scolopendra apd its musculatory system." With 3 plates. Copenbagen, 1883. 
Furthermore, I ought to remark that at present I reckon the "lamina dorsalis" as scutum dorsale to the fourth metamer. (the ventral part of which is the raptorial legs or pedes prensorii with their sternum), and the "lamina præbasalis" as scutum dorsale to the third metamer (of which the mandibles are the exponents). In the "Myriapoda Musæi Hauniensis, I. Geophili," p. 9, I have explained the "lamina basalis" in the same manner as here; but there I referred the "lamina præbasalis" to the maxillæ, or the "pedes maxillares primi paris " as I then named them, because the ventral part of the true third metamer was, at that time, quite overlooked, not by me alone, but by all authors. But the alteration of the explanation is no reason for altering the term.

With regard to the classification of the Myriapoda or of the Chilopoda generally, there is but little reason for inquiring into the matter more extensively, particularly as no species of the aberrant genera Scolopendrella, Polyzonium (and Peripatus), are among those which are the object of my present investigations. I will only refer to my previous papers, in which I have strenuously opposed the views of Alex. Brandt, when he regards the genus Scutigera to be a special type of no less systematic value than all the other Chilopods together. For this reason also, I united the Scutigerini and Lithobiini in one single family, the Lithobii, regarding their systematic value as not being greater than that of the Scolopendræ and the Geophili. At present I willingly admit that I have rather exaggerated, in my endeavors to prove the intimate relation between Scutigera and Lithobius, and that I have thus in some degree underrated the systematic value of Scutigera; and, therefore, I prefer now to consider the genus Scutigera to be a separate family, of similar value to the other families of the Chilopoda. But, on the other hand, I must maintain that Scutigera and Lithobius are much more closely related reciprocally, than to either Scolopendra or Geophilus, and therefore I prefer, according to Erich Haase, to unite the four families into two groups, the Anamorpha and the Epimorpha, rather than, according to Latzel, to arrange them into a straight line.

\section{Tribus ANAMORPha.}

Segmenta corporis pedifera 15 , inter se inæqualia.

Pedes longi vel longissimi; omnes coxis magnis, manifestis, tarsis bivel- multi-articulatis. 
Antennæ articulis multis vel plurimis.

Oculi ocellis paucis vel plurimis, aggregatis vel compositis.

Pedes prensorii articulo secundo et tertio manifestis, integris.

Spiraculorum paria nulla vel maxime 6 .

Genitalia feminea forcipe externo armata.

Pullus ex ovo nuper exclusus pedum paribus 7 modo instructus.

The tribus Anamorpha thus corresponds with the family Lithobii, as I have proposed this family in "Danmark's Scolopendrer og Lithobier." Naturh. Tidsskr. 3 R., 5 B., p. 246, and the alterations which I have made in the characters here are rather insignificant, although I will remark upon the following.

By the addition of "corporis" to the first characters, I intended to argue that the pedes prensorii or raptorial legs, together with their segment or metamer, cannot be reckoned with the true segments and the true limbs of the body; and I must particularly urge this point, as I have given up the denomination "pedes maxillares" in which an explicit reference to the head was contained. To the second character I have added "omnes coxis magnis, manifestis," by which I maintain that the last pair of legs has large coxæ of the same shape as those of the other legs, and with or without excretorial pores. In the next place I have determined the characters concerning the spiracles more exactly, but for further explanation I must refer to the characters of the family (or genus) Scutigera. The characters concerning the raptorial legs will be treated of more minutely under the second principal group, the Epimorpha. In conclusion $I$ have added the last two characters of Haase.

As to the rest, with regard to my character "tarsis bi- velmulti-articulatis," I must make the following remark. The typical number of joints of the limbs, both in the Chilognatha and the Chilopoda is seven, and it is thus stated by recent authors, ${ }^{*}$ and particularly by Latzel, in his most valuable work on the Austrian Chilopods. $f$ According to the rule, these seven

\footnotetext{
* Newport, on the contrary, reckons only six joints in the limbs of the Myriapods, overlooking, or not regarding as a joint the trochanter. "Monogr. Class. Myriap. Trans. Linn. Soc. London," xix, p. 283. Wood has also in this point followed Newport. " Myriap. North Amer. Trans. Amer. Phil. Soc.," xiii, p. 14l142.

†"Die Normal zahl der Fussglieder ist sieben," so he writes in spaced types. "Myriap, Oesterr, Ung, Mon, , p, 11."
} 
joints are regarded as homologous with corresponding joints of the limbs of the Insects, in this manner :- the first joint is explained to be the coxa, the second the trochanter, the third the femur, the fourth the tibia, and the last three joints to be the tarsus or the foot. (Compare also Latzel, l. c.,p. 12.) As far as number goes, this explanation is very excellent, particularly as most insects have the same number of divisions, five, and a great multitude of insects precisely three joints in the foot, but in reality it is very superficial and incorrect. Thus, when we regard the limbs of insects as the props which support the body and carry it over the ground, four divisions are necessary, viz : the first, by which the prop is fastened to the body, $i$. e. the coxa; the second, which extends the prop beyond the median line of the animal, i. e. the femur (and the trochanter); the third, by which the body is raised from the ground, $i$.e. the tibia; and the fourth which supplies the necessary hold upon the ground, $i$. e., the tarsus. Yet it will clearly appear that the matter depends on the arrangement and not on the number or the series of the joints ; for the number varies not only in the fourth division, the tarsus, but also in the second (the femur). But still, no one has ever regarded the femur as a tibia, when, the trochanter being bipartite, as in many Hymenoptera, the femur became the fourth and not, as is usual, the third joint in the limb, nor the tibia as the first joint of the tarsus, in the same case. Yet of these four divisions, the second is usually divided into two, the fourth into from two to five joints, beside the claw or claws. The third division, the tibia, is unipartite, or whole, in the true Insects, but in the Spiders, it is bipartite, and the joints here are denominated "patella" and "tibia"; so also in the Chilopoda. Among the Chilopoda, however, no genus can prove more clearly than Scutigera that the fifth and fourth joints are of one set, and that the fifth joint cannot be referred to the tarsus, as well as the sixth and the seventh, for in this genus, the fifth and sixth joints are bent into an angle, and are also very different in structure; furthermore, the fifth joint is, like the tibia of the true Insects, formed with distinct, although small, calcars. The two joints of which the tarsus of the Chilopods thus consists, are most frequently separated, more or less distinctly, but often, as in the Geophili and in some Scolopen. 
d rini (Cryptops), they are coalesced, or on the contrary, as in the Scutigera, they are both divided into a great number of joints. I have already suggested this explanation in "Danmark's Geophiler," where it is said in the diagnosis of the Geophili, l. c. p. \$1, "tarsis integris," and immediately after : "Det normale Antal Led i Myriapodernes Been kan antages at vaere syobaacte hos Chilognather og Chilopoder;" with regard to the Scolopendrini and Lithobii (Anamorpha), in "Danmark's Scolopendrer og Lithobier," p. 242 and 244, I have maintained this view, and in the "Myriapoda Musæi Hauniensis, I. Geophili," p. 7, I have reiterated my former explanation of the limbs of the Geophili. In the following table, I will set forth the terminology which I shall use in this paper, together with that which some other authors have used.

\begin{tabular}{|c|c|c|c|c|c|c|}
\hline & 1st Joint. & 2d Joint. & 3d Joint. & 4th Joint. & 5 th Joint. & $6 \mathrm{th}-7 \mathrm{th}$ Joint \\
\hline $\begin{array}{l}\text { Newport, } \\
\text { L. Koch,* } \\
\text { Torath, † } \\
\text { Latzel, } \\
\text { Author, }\end{array}$ & $\begin{array}{l}\text { Coxa, } \\
\text { 1. Hüften- } \\
\text { glied, } \\
\text { Coxa, } \\
\text { Hüfte, } \\
\text { Coxa, }\end{array}$ & $\begin{array}{l}\text { 2. Hüften- } \\
\text { glied, } \\
\text { Schenkel- } \\
\text { ring, } \\
\text { Trochanter, }\end{array}$ & $\begin{array}{l}\text { Femur, } \\
\text { Oberschenk- } \\
\text { el, } \\
\text { Femur, } \\
\text { Schenkel, } \\
\text { Femur, }\end{array}$ & $\begin{array}{l}\text { Tibia, } \\
\text { Unterschen- } \\
\text { kel, } \\
\text { Tibia prima } \\
\text { Schiere, } \\
\text { Patella, }\end{array}$ & $\begin{array}{l}\text { Tarsus, } \\
\text { 1 Tarsalglied } \\
\text { [da, } \\
\text { Tibia secun- } \\
\text { 1 Tarsalglied } \\
\text { Tibia, }\end{array}$ & $\begin{array}{l}\text { Metatarsus. } \\
\text { 2-3 Tarsal- } \\
\text { glied. } \\
\text { Tarsus. } \\
\text { 2-3 Tarsal- } \\
\text { glied. } \\
\text { Tarsus. }\end{array}$ \\
\hline
\end{tabular}

With regard to the denominations of Newport, I will call to mind a correction, which, for the rest, Newport himself has made in the second part of his monograph, saying, l. c., p. 351, footnote:

"In the first part of this paper, page $283-4$, the joint that articulates with the tibia has been described by a mistake as the metatarsus instead of the tarsus, and the remaining joints as tar. sal instead of metatarsal."

In the dissertation "Schlesiens Chilopoda I. Chilopoda anamorpha," 1880, Haase seems to have followed me, at least, he says in the character of his subordo prior, the Chilopodo anamorpha, "tarsis bi- vel multi-articulatis," l. c., p. 6 , but in the paper published immediately afterward, "Beiträge zur Phylogenie und Ontogenie der Chilopoden," he must have joined Latzel's side, for he says, 1. c., p. 11, "Die Beine der Chilopoden lassen sich stets auf das typische Insectenbeine zurückführen

* “Die Myriapodengattung Lithobius," 1862.

$\dagger$ † Myriapoda Africæ australis, in Musæo Regio Holmiensi asservata," 1872. 
und bestehen normal wie dieses aus Coxa, Trochanter, Femur, und einem 3-gliedrigen Tarsus."

\section{Fam. SCUTIGERINI.}

Laminæ dorsales alternæ manifestæ, in medio incisæ, alternæ evanidæ.

Pedes longissimi, tarsis multi-articulatis, unguis singuli, processlis binis setiformibus instructi.

Antennæ setaceæ, articulis plurimis compositæ.

Oculi ocellis plurimis compositi.

Spiracula nulla. Stomata septem.

Palpi maxillares quadriarticulati ungue nullo.

Laminæ dorsales segmenti septimi atque octavi coalita.

Sternum metameri quarti bipartitum ; setis octo longis armatum.

Coxæ pedum posteriorum simplices (poris execretoris nullis).

The fifteen segments of the body have each one pair of limbs and differ bui very little among themselves with regard to the size of the laminæ ventrales; but, on the contrary, the difference between the dorsal part of the segments is very great, the laminæ dorsales of six segments, i. e., the $2 \mathrm{~d}, 4$ th, 6 th, 9 th, 11 th and 13 th, not being fully developed, but only represented by a membranous fold which is attached to the front edge of the lamina dorsalis of the following segment, while the laminæ dorsales of the eighth and ninth segments coalesce into a common large plate. Thus the number of distinct, well-developed segments in the Scutigerini is only eight. With regard to the second family of this tribus, the Lithobiini, I must remark that the same six laminæ dorsales, which in the Scutigerini are evanescent, in the Lithobiini become abruptly smaller than the remaining laminæ, while the two large well-defined laminæ dorsales of the seventh and eighth segments in the Lithobiini correspond with the large coalesced lamina of the same segments in the Scutigerini.

The posterior edge of the first seven well-developed laminæ dorsales is deeply excavated in the median line, and in this excavation a narrow chitinous ring encloses the orifice (stoma) of a duct into which a number of glandular tubes open from both sides. A controversy of some length has lately taken place with regard to the function of these stomata and of the glandular organs situated behind them, which are either supposed to be spiracles and tracheæ, or regarded only as mere glands. The second view has been several times supported by the author, and I will only refer to my last paper in the controversy: "De 
formeentlige Aarde draetsredskaber og deres Mundinger (Stomata) hos Slaegten Scutigera" ("The supposed respiratory organs and their orifices (stomata) in the genus Scutigera"). Vid. Medd. Naturh. Foren. Kjobenhavn, 1882, p. 88.

At present, I will only point out that the number of stomata is seven, and that of the pairs of spiracles in Lithobius six, and that if the stomata were homologous with the spiracles in the other Chilopods, certainly the first segment of the body in Scutigera should have spiracles or coalesced spiracles, while that segment in the other Chilopods should be without these respiratory organs.

The limbs are very long, or much elongated, the different joints being all, except the trochanter, elongated, and the last two, the tarsus, being, besides, divided into a great number of little joints. The first seven pairs of legs are nearly of the same length, but each following pair increases in length, and the hindmost pair, particularly in the male, is abruptly elongated into a fine hair. The two joints of the tarsus are each divided into a great number of badly defined little joints, but the length and thickness of the first joint is always greater than that of the second; on the contrary the number of little joints is much greater in the second tarsal joint than in the first, and we find here even four or five hundred such joints (Latzel, l. c., p. 27). The length of these little joints varies very much in the same species, nay, even in the same specimen, and, besides, no established order can be detected, so that we cannot possibly follow Newport, when he makes use of the proportion between the lengths of the first two of these little joints as characters of species. I have found the proportion varying in the same species from $1: 1$ to $1: 6$, but never have I seen the second joint larger than the first; also, in the same specimen, I have found the proportion $3: 1$ in one leg, but $1: 1$ in the other. Without going further, the circumstance that the different authors who have used this character have mentioned a different proportion in the same species demonstrates that the proportion is not so fixed as Newport intimates (l. c., p. 351).

Each leg has a single claw, but this claw has two long setiform processes, which run along the inner side of the claw, from the base; the length of the processes seem to be from one-half to 
four-fifths of the length of the claw. The anal legs seem to be clawless.

The antennæ are setiform, very long, and consist of several hundreds of very minute joints, which are, however, united into two or three fully distinguishable principal joints.

'The eyes are large, very prominent and composite, the number of ocelli may be some two hundred or more.

In the preceding pages I have already mentioned the want of spiracles.

The palpi maxillaries are long, slender, four-jointed; the first three are furnished on the front edge with long stout bristles. The fourth or last joint has preserved the same shape as the preceding ones, and has not, as in the Lithobiini and the other Chilopoda, taken the shape of a claw. The two halves of the sternum of the (fourth) metamer are not united; each part bears four long stout bristles on the front edge.

The coxæ are all plain, without glands or glandular pores.

The forceps of the female organs of generation consists of a pair of styli, the first joints of which are nearly joined together with the posterior half of their inner edge, while the forward part is separated and often furnished with a small brush of hair at the corner. As these styli are bent against each other, the shape of the forceps and of the sinus between the two styli is altered and therefore no characters of great value can be drawn from this organ.

Most of the characters in use to-day are valueless, except the color and the proportions of the length of the legs and of the antennæ to the body; we seldom find true characters used, but ordinarily the descriptions are drawn now from one part of the body, now from another. Even the characters employed by such accurate observers as Torath and Latzel are partly due either to a fortuitous want, or are characters common to the whole genus. It is evident that a very great number of different species are needed, before we can hope to find the true special characters. Yet it is far from my intention to claim that I have been more fortunate than my predecessors, and although I believe I have shown many deficiencies in the characters in use, I do not mean that I myself have found the right ones; but I also have had too little material and this must be my excuse. PROC. AMER. PHILOS. SOC. XXIII. 122. v. PRINTED DECEMBER 17, 1885. 
Although the genus Scutigera is very interesting, the different species of the genus are but little so; and the characters which they offer are, as I have just asserted, often very few and without value. Besides, the antennæ and the legs, particularly the anal legs, are excessively fragile and are often wanting, even in living specimens; and thus many of the specimens which are preserved in museums are more or less destitute of the organs from which the chief characters are drawn. Frequently we find specimens deprived of all their external organs. Species founded on such organs are indeed of no great value, but nevertheless they are distinguishable, and I myself have proposed such a new species.

\section{Scutigera serratipes.}

Scutigera serratipes Gervais, Walckenær Hist. Nat. Ins. Apt. iv, p. 221. ? Scutigera Templetoni Humbert, Essai Myriap. Ceylan, p. 8, pl. i, fig. $1,1 \mathrm{a}-1 \mathrm{~b}$.

Latiuscula, ante et post paulum angustata, convexa (,) livida, vittis duabus lateralibus latissimis griseis mediaque post paulum angustata rufo-livida notata, antennis tarsisque flavis, cingulis patellarum manifestius, tibiarum binis obsoletius cœrulescentibus; manifesto tuberosa, spinulis in dorso (extra lineam mediam glabram) subseriatis granulisque perminutis scabriuscula.

Lamina cephalica fere æque longa ac lata, post late minus profunde impressa, ante canaliculata, sulcis duobus rectis transversis atque sulco singulo antico curvato exarata ; alte marginata (,) margine læviuscula, fimbriata.

Antennæ corpore sesqui longiores.

Laminæ dorsales alte marginatæ, margine densissime spinuloso, margine postico in angulum obtusum producto, obscure flexuoso, in medio iate sinuato; lamina ultima latiuscula, lateribus paulım flexuosis, sat angustata, post late rotundata, obscure emarginata.

Stomata in æquum porrecta, longa, stomate primo quam linea media laminæ dorsalis manifesto breviore.

Carinæ pedum alte expressæ, densissime spinulosæ.

Pedes paris ultimi tenuissimi, corpore plus duplo longiores (fere 11:5); tibia a tarso bene discreta, manifesto clavata, aculeis binis longiusculis, subæqualibus armata.

Forceps feminæ longiusculus, articulo altero quam priore multo breviore (fere $3: 4$ ).

Long. $35 \mathrm{~mm}$.

Hab. At Pennaculum, South India, Mr. Scudder; the Isle of St. Mauritius, Mr. Pike. 


\section{Scutigera Castanea, n. sp.}

Angustiuscula, ante multum, post paulum angustata, valde convexa; castanea, concolor ; tuberosa, spinis in dorso medio subseriatis granulisque perminutis dense scabricula.

Lamina cephalica multo longior quam latior $(5: 4)$, in crucem impressa, margine læviusculo.

Antennæ desurt.

Laminæ dorsales alte marginatæ, margine manifesto crenulato, margine postico in triangulum obtusum producto, in medio late sinuato; lamina ultima lata, lateribus rotundatis, valde angustata, post integra.

Stomata in æquum porrecta, longa, stomate primo quam linea media laminæ dorsalis fere sesqui breviore.

Pedes desunt.

Forceps feminæ longiusculus, angulo interiore articuli prioris longius penicillato.

The type of this species was deprived of all its legs and the antennæ.

Hab. Koolloo, Mr. Carleton (the specimen was found in a box together with the last mentioned species of this genus, Scut. microstoma).

\section{SCutigera FORCEPS.}

?. Selista forceps Raffinesque, Ann. of Nature, i, p. 7.?

Cermatia coleopterata Say, Journ. Acad. Nat. Sc. Philada., ii, p. 5. Cermatia floridana Newport, Trans. Linn. Soc. Lond., xix, p. 353. Scutigera floridana Gervais, Walck. Hist. Nat. Ins. Apt., iv, p. 225. Cermatia forceps Wood, Journ. Acad. Nat. Sc., new ser., v, p. 132.

Wood, Trans. Amer. Philos. Soc. xiii, p. 145, pl. iii, fig. 1, 1a.

? Cermatia Mexicana Saussure et Humbert, Etud. s. Myriap., p. 112, tab. v, fig. 3, 3a, b. p.

Latiuscula, ante vix post paulum angustata, minus convexa vel convexa ; supra viridi-lutea, vittis tribus angustis, fuscis vel cœrulescentibus notata, patellis tibiisque cingulis binis cœrulescentibus, per paria sensim latioribus atque manifestioribus ornatis ; obscure tuberosa, spinulis sparsis subseriatis (extra lineam mediam longitudinalem lævem) scabriuscula.

Lamina cephalica post late, minus profunde impressa, ante canaliculata, carina media obscuriore in transversum notata, minus alte marginata, margine læviusculo, sparse fimbriato; manifesto latior quam longior (fere $8: 7$ ).

Antennæ pertenues, corpore plus sesqui longiores (feminæ $11: 7$; mari $5: 3)$. 
Laminæ dorsales minus alte marginatæ, margine sparse spinuloso, margine postico late rotundato, in medio latissime sinuato ; lamina ultima angustiuscula, lateribus rotundatis, sat angustata, post breviter rotundato, in medio obscure sinuato.

Stomata præter primum in æquum fere porrecta, parva vel mediocria, stomate primo quam linea mediæ laminæ dorsalis bis vel ter (fere $2: 5$ ), breviore.

Carinæ pedum minus alte expressæ, sparse spinulosæ.

Pedes paris ultimi pertenues, corpore bis vel ter longiores (fere $5: 2$ ), tibia a tarso bene discreta, obscure clavata, aculeis binis longiusculis, inæqualibus armata.

Forceps feminæ breviusculus, angulo interiore articuli prioris penicillato, articulo altero quam priore multo breviore (fere $3: 4$ ).

Long. $28 \mathrm{~mm}$.

I have compared typical specimens of Mr. Wood.

Hab. Beaufort, N. C.; Texas, Mr. P. W. Putnam; Boston, Mass., Mr. Corbett (another specimen from Boston was labeled "found Dec'br 27 living in a tobacco store in Boston importing tobacco from the Southern States, perhaps imported ").

\section{Scutigera Argentina.}

Cermatia Argentina Humbert et Saussure, Rev. et Mag. Zool. 2 sér. xxii, p. 202.

Saussure et Humbert, Etud. s. Myriap. p. 113. Tab. v, fig. 2, 2a.

Angusta, ante et post vix angustata, compressa vel compressiuscula ; obscure brunnea, pedibus flavis, sanguineo-plagiatis; parum tuberosa, spinulis in series subdigestis scabriuscula.

Lamina cephalica in foveam parum altam impressa, in medio sat profunde canaliculata, sulco transverso, valde arcuato obscure impressa; minus alte marginata, margine læviusculo, sparsissime fimbriato; vix latior quam longior.

Antennæ desunt.

Laminæ dorsales minus alte marginatæ, margine dense crenulato, margine postico rotundate angustato, in medio in angulum acutum inciso ; lamina ultima angustiuscula, lateribus rotundatis, angustata, post integra.

Stomata fere propendentia, perparva, stomate primo quam linea media laminæ dorsalis multoties breviore.

Carinæ pedum minus alte expressæ, sparsissime spinulosæ.

Pedes paris ultimi desunt.

Forceps feminæ breviusculus, angulo interiore articuli prioris aculeo penicilloque brevibus armato, articulo altero quam priore paulo breviore.

Long. $18 \mathrm{~mm}$.

Hab. Cordova, Argent., Mr. Davis (one single specimen). 


\section{Scutigera nigro-vittata, n. sp.}

Latiuscula, ante et post paulum angustata, convexiuscula ; flava, vittis duabus latis, nigris, lateralibus prætereaque vittis duabus interioribus capiti notata, femoribus patellis tibiisque infra fasciis binis nigris, per paria sensim manifestioribus atque latioribus signatis, stomatibus nigris; obscure tuberosa, spinulis sparsis, in series subdigestis (extra lineam mediam longitudinalem glabram) granulisque perminutis scabriuscula.

Lamina cephalica post profunde impressa, ante canaliculata, sulcis duobus in transversum impressa; minus alte marginata, margine sparsius fimbriato; fere æque longa ac lata.

Antennæ tenues, truncatæ.

Laminæ dorsales minus alte manginatæ, margine densius fimbriato, margine postico sat breviter rotundato, in medio late sinuato; lamina ultima angustiuscula, valde angustata, post brevissime rotundata.

Stomata paulum declivia, parva, stomate primo quam linea media laminæ dorsalis bis vel ter breviore.

Carinæ pedum minus alte expressæ, spinis sparsis vel sparsioribus setisque serratæ.

Pedes paris ultimi desunt.

Forceps feminæ longiusculus, latere interiore articuli prioris sparsius hirsuto, articulo altero quam priore plus sesqui breviore (fere $3: 5$ ).

Long. $25 \mathrm{~mm}$.

\section{Hab. Panama.}

\section{Scutigera microstoma, n. sp.}

Latiuscula, ante et post paulum angustata, parum convexiuscula ; flava, vitta media, lata, gemina, fusca, marginibus laminarum obscurioribus ; læviuscula, sparsissime hirsuta, granulis perminutis aspera.

Lamina cephalica post in figuram ypsiliformem obscure impressa, ante leviter sulcata, parum alte marginata, margine sparse, brevius fimbriato; multo longior quam latior $(6: 5)$.

Antennæ tenues vel pertenues, corpore paulo longiores (fere $11: 10$ ).

Laminæ dorsales parum alte marginatæ, margine obscure crenulato, margine postico rotundate angustato, in medio late sinuato; lamina ultima angustiuscula lateribus flexuosis, paulum angustata, post latissime rotundata, in medio obscurissime sinuata.

Stomata declivia, parva, stomate primo quam linea media laminæ dorsalis bis vel ter breviore.

Pedes paris ultimi desunt.

Forceps feminæ breviusculus, angulo interiøre articuli prioris breviter penicillato, articulo altero quam priore vix breviore.

Long. $21 \mathrm{~mm}$.

Hab. A place 70 miles from Amballa, India, Mr. Carleton (10 specimens); Koolloo, Mr. Carleton (4 specimens in a box together with Scut. castanea). 


\section{Fam. LITHOBIINI.}

Laminæ dorsales omnes manifestæ (alternæ minores), integræ.

Pedes longi, tarsis biarticulatis (in pedibus prioribus sæpe indistincte); ungues bini (in pedibus posticis sæpe singuli), ungue majore processu simplice, parvo armato.

Antennæ articulis multis vel permultis.

Oculi ocellis paucis vel multis, aggregatis.

Spiracula manifesta (sena).

Palpi maxillares triarticulati, ungue armati.

Laminæ dorsales segmenti septimi atque octavi discretæ.

Sternum metameri quarti integrum ; prosternum ante integrum vel indentes incisum.

Pori excretorii in coxas quaternas (vel quinas) ultimas intrusi.

For further explanation of the characters of this family I refer to my preceding essays on the Lithobii ("Danmarks Scolopendrer og Lithobier," Naturh. Tidsskr. 3 R. 5 B., p. 247, and "Myriapoda Musæi Hauniensis ii, Lithobiini," ibid. 3 R. 8 B., p. 281) and to the preceding pages of this paper.

\section{Gen. Lithobius.}

Labrum liberum, in medio profunde incisum, dentatum, lateribus fimbria lata et densa, e laciniis setiformibus, racemosis facta, instructis.

Labium setis racemosis et simplicibus instructum, processibus labii sat magnis.

Palpi maxillares ungue tri- vel quinque-partito armati.

Mandibulæ serie abbreviata setarum minorum, racemosarum pone setas majores crenulatas armatæ.

Oculi ocellis paucis vel multis.

Pedes omnes vel plurimi calcaribus armati, maxime unguibus binis armati.

Genitalium femineorum unguis intus excavatus, integer aut bi- vel trilobus.

The characters which are here given of the genus Lithobius for the most part conform with those I have proposed in Myriap. Mus. Haun. ii, Lithobii, p. 283, and the apparent great difference arises solely from the introduction of my new terminology and from the altered order of the parts of the mouth, both of which my late investigations have made necessary.

Lamina dorsalis $6,7,9,11,13$ angulis productis.

Pedes anales ungue singulo armati.

Pori coxales in series plures digesti.

Genitalium femineorum unguis tripartitus.

Pedum analium coxæ calcare armatæ. 


\section{Lithobius multidentatus.}

Lithobius multidentatus Newport, Trans. Linn. Soc. Lond., xix, p. 365.

Gervais, Walck., Hist. Nat. Ins. Apt., iv, p. 236.

Bothropolys nobilis Wood, Journ. Acad. Nat. Sc., new ser., v, p. 15.

Bothropolys multidentatus Wood, Trans. Amer. Phil. Soc., xiii, p. 152.

Dilute brunneus, plagis binis magnis laminarum dorsalium, capite antennisque præter summam apicem fuscescentibus; robustus vel sat robustus, ante obsolete, post manifesto rugulosus; capite subobcordato, vix latiore quam longiore, sublævi. Antennæ longiores, articulis longis, 20-22 articulatæ.

Oculi ocellis $20-30$, in series $4-6$ digestis.

Dentes prosternales septeni vel octoni.

Pori coxales numerosi, in series $3-4$ subdigesti.

Pedes corporis primi paris calcaribus $2,2,1$; pedes anales calcaribus 1, 3, 2, 1 armati.

Pedes postici sat longi.

Genitalium femineorum unguis latus, manifesto tripartitus, aculeis interioribus quam exterioribus multo brevioribus.

Long. 22-25 mm.

Hab. Warwick, Mass. (3 typical specimens of Dr. Wood); Marlow, N. H.; near to the Mammoth Cave, Ky., Mr. Putnam; Michigan, Mr. E. P. Putnam.

Lamina dorsalis 7, 9, 11, 13 angulis productis.

Pedes anales ungue singulo armati.

Pori coxales pauciores, in seriem singulam digesti.

Pedes penultimi unguibus binis armati.

Pedum analium coxæ calcare singulo, parvo armatæ.

\section{Lithobius Latzeli, n. $\mathrm{sp}$.}

Castaneus vel rufo-brunneus, laminis ventralibus pedibusque flavescentibus ; robustus, sublævis, capite lato, multo latiore quam longiore (fere $4: 3$ ), vix punctato. Antennæ breviusculæ, paulum attenuatæ, 34-articu. latæ.

Oculi ocellis $45-48$, in series $8-9$ obliquas digestis.

Dentes prosternales octoni.

Pori coxales $5,7,6,4-5,6,6,5$, magni, plerique transversales.

Pedes corporis primi paris calcaribus $2,3,1$; pedes anales calcaribus 1 , $3,3,2$ armati.

Pedes postici breviusculi, vix inflati.

Long. $23 \mathrm{~mm}$.

Mas: Pedum analium femur patellaque infra sulco longitudinali excavata.

Hab. Crandall, Virginia. 
Lamina dorsalis 9, 11, 13 angulis productis.

Pedes anales ungue singulo armati.

Pori coxales pauciores, in seriam singulam digesti.

Pedes penultimi unguibus binis armati.

Pedum analium coxæ calcare nullo.

\section{Lithobius forficatus (Linn.).}

Lithobius forficatus Newport, Trans. Linn. Soc. Lond., xix, p. 367.

Lithohius Americanus Newport, ibid, xix, p. 365, tab. xxxiii, fig. 29.

Lithobius multidentatus Wood, Journ. Acad. Nat. Sc., new ser., v, p. 13.

Lithobius Americanus Wood, ibid., p. 14.

Wood, Trans. Amer. Phil. Soc., xiii, p. 148.

Castaneus vel brunneus, laminis ventralibus pedibusque flavis, robustus, sat rugulosus, sæpissime subglaber, interdum hirsutulus, præsertim post, capite magno, subquadrato. Antennæ sat longæ, 36-48-articulatæ.

Oculi ocellis $22-35$, in series $5-8$ digestis.

Dentes prosternales quini vel septeni.

Pori coxales $6,6,6,5-12,10,9,8$, plerique transversales.

Pedes corporis primi paris calcaribus $2,3,2$; pedes anales calcaribus 1 , $3,3,2$ armati.

Pedes postici longiores, paulum inflati.

Genitalium femineorum unguis trilobus.

Long. 14-26 mm.

For the characteristics of the not fully developed Lithobius forficatus I refer to my Myriap. Mus. Haun., ii, p. 315 and 316, and to the elaborate essay of Latzel, l. c., p. 57 ; also for the table of synonymys I refer to Ant. Stuxberg, who in his "Lithobioidæ Americæ Borealis " (Ofvers. Kgl. Vet. Akad. Förh., 1875, No. 3, p. 27), gives a list of the synonyms of this animal perhaps complete to his time.

The species is doubtless the most common of all Lithobii in the eastern part of North America, and the Museum of Comparative Zoölogy also possesses numerous specimens not alone from Massachusetts, but also from other places, as Halifax, N. S.; Britain Island, N. S.; Amherst, N. H., Mr. A. M. Edmands ; Bee Spring, Ky., Mr. F. G. Sanborn; Anticosti.

Lamina dorsalis 11, 13 angulis productis.

Pedes anales unguibus binis armati.

Pori coxales pauciores, in seriem singulam digesti.

Pedes penultimi unguibus binis armati.

Pedum analium coxæ inermes. 


\section{Lithobius Cantabrigensis, n. sp.}

Flavus, capite paulo obscuriore; gracilis, sublævis, subglaber, capite - subobcordato, fere æque longo ac lato. Antennæ breves, 35-articulatæ, articulis perbrevibus.

Oculi ocellis 8 , in series 2 digestis.

Dentes prosternales bini.

Pori coxales 2, 3, 3, 2-3, 4, 3, 2.

Pedes corporis primi paris calcaribus $0,0,1$; pedes anales calcaribus 1 , 3, 1, 0-1, 3, 2, 1 armati.

Pedes postici longiusculi, paulum inflati.

Genitalium femineorum unguis trilobus, aculeis brevibus, acutis, interioribus quam exterioribus manifesto brevioribus.

Long. $10.5 \mathrm{~mm}$.

\section{Hab. Cambridge, Mass., Mr. H. H. James.}

Laminæ dorsales omnes angulis rectis.

Pori coxales pauciores, in seriem singulam digesti.

Pedum analium coxæ calcare singulo armatæ.

\section{Lithobius Jowensis, n. sp.}

Brunneus, capite cum antennis obscuriore, laminis ventralibus pallidioribus, pedibus flavis ; sat gracilis, sublævis, pedibus densius pilosis, capite subobcordato, manifesto latiore quam longiore (fere $8: 7$ ). Antennæ breviusculæ, 23 articulatæ, articulis pluribus brevibus.

Oculi ocellis $12-15$, in series $3-4$ digestis.

Dentes prosternales quaterni.

Pori coxales 4, 5, 5, 4, rotundati.

Pedes corporis primi paris calcaribus 2, 1, 1; pedes paris antepenultimi (pedes anales penultimique desunt) calcaribus 1, 3, 3, 1 armati.

Pedes postici breviusculi.

Genitalium femineorum unguis integer, aculeis minus tenuibus, longitudine subæqualibus.

Long. $13.5 \mathrm{~mm}$.

The specimen which I had to examine was in a bad condition, and particularly the last pairs of legs were lost.

\section{Tribus EpImorpha.}

Segmenta corporis pedifera pauciora vel numerosa, inter se subæqualia vel æqualia.

Pedes sat longi vel breves, coxis parvis vel evanidis, tarsis integris vel articulatis.

Antenuæ articulis paucioribus.

Oculi nulli vel ocellis paucis.

Pedes prensorii articulo secundo atque tertio parvis vel mimis, in latere exteriore evanidis vel interruptis.

PROC. AMER. PHILOS. SOC. XKIII, 122. w. PRINTED DECEMBER 16, 1 \& 85. 
Spiraculorum paria segmentis pediferis numero subæqualia, vel saltem 9-10.

Genitalia feminea externa nulla.

Pullus ex ovo nuper exclusus pedibus secundum speciem normatis instructus.

\section{Fam. SCOLOPENDRINI.}

Segmenta pedifera 21-23, inter subæqualia.

Pedes sat longi, tarsis, saltem ultimis binis, articulatis.

Antennæ 17-30 articulatæ.

Oculi nulli vel ocellis paucis.

(Pedes prensorii articu'o secundo atque tertio (sæpissime) in latere exteriore evanidis vel interruptis.)

Lamina basalis sæpissime evanida.

Spiraculorum paria plerumque 9 vel 10.

The number of the joints of the antennæ is seldom more than 22 or 23 ; yet in some true Scolopendræ, as in Sc. heros, I have found a greater number, and thus I have been compelled to place the limit as high as 30 joints.

As a rule, the second and the third joint of the raptorial legs (pedes prensorii) are very small. Furthermore, regularly the rings of these joints are not whole but interrupted at their dorsal or outermost side; yet, in the genus Cryptops the ring of the third joint is whole, and thus in this genus the dorsal side of the first and of the fourth joint of the raptorial legs is not as in the other genera united or confined.

Gervais, in his tables of the genera of the Scolopendrini, 1.c., p. 243, proposes a genus Monops, and in the description of the Cryptops nigra, l. c., p. 294, he retains this name, but without giving a real description of the genus he only indicates that a pair of eyes is found by him. Now it would be of great interest to have a more full investigation of this new genus; I do not dare to say that the eyes are wanting, but on the other hand the family Scolopendrini forms such a compact and distinct group of animals, either wanting eyes, or having them to the number of four pairs, that it is not likely that in this family one species alone would have one pair; and, therefore, I believe that the genus Monops must be in many other characters different from the genus Cryptops, if the eyes in reality exist.

In the lately published genus Plutonium* the number of spi-

* Cavanna, Bull. Soc. Ent. Ital., xiii, p. 169, ff. tab. 1. I have not seen this paper, but, according to Bertkau, the genus seems tu relate to Opisthemega. 
racles is said to be 19 on each side, but in the other genera no more than 10 pairs are found.

\section{Segmenta pedifera 23.}

\section{Gen. Scolopocryptops.}

Scolopocryptops Newport.* Trans. Linn. Soc. Lond., xix, p. 407.

Lamina cephalica laminam primam dorsalem partim obtegens.

Oculi nulli.

Antennæ tenuiusculæ, subfiliformes, 17-articulatæ.

Labri fimbria longa, intus e setis ad apicem fissis facta.

Labii processus subteretes, barba e setis partim fissis facta instructi ; palporum fimbria e setis paulum uncinatis vel clavatis facta.

Palporum maxillarium unguis in latere interiore dentibus 13-15 manifestis armatus; fimbria digitalis unguem procul explens, setis parum uncinatis.

Mandibulæ ante pectinibus 8 juxta et pone lamellam singulum, latam, dentatam coarctatis instructæ.

Metameri quarti sternum integrum, robustum; prosternum parum prominens subtruncatum, vel in angulos breviores productum; pedes prensorii articulo secundo et tertio minimis, interruptis.

Segmentum septimum absque spiraculis.

Spiracula profunda, magna, subrotunda vel breviter ovalia, perpendicularia.

Pleuræ posticæ infra porosæ, in spinam longam post productæ.

Pedes anales elongati, quinquearticulati, articulo primo (femorali) spinigero, ungue minus curvato, subgracili, ad basis unguiculis binis minimis armato.

\section{SCOLOpocRyptops sexspinosus.}

Cryptops sexspinosus Say, Journ. Acad. Nat. Sci. Philad., ii, p. 112. Scolopocryptops sexspinosa Newport, Trans. Linn. Soc. Lond., xix, p. 407. Gervais, Walckenaer Ins. Apt., iv, p. 297.

Wood, Journ. Acad. Nat. Sci. Philad., new ser., v, p. 37.

Wood, Trans. Amer. Phil. Soc., xiii, p. 172.

Kohlrausch, Arch. f. Naturg. Jahrg., 47, p. 54. Porath, So. Vet. Akad. Handl. Bih., B. 4, p. 26.

Scolopocryptops spinicauda Wood, Journ. Acad. Nat. Sci. Philad., new ser., v, p. 39.

Wood, Trans. Amer. Phil. Soc., xiii, p. 174.

* This name is formed by Newport against the chief rules of nomenclature; yet it has always been received, and therefore I also shall make use of it. 
? Scolopendropsis helvola C. L. Koch, Die Myriap., ii, p. 34, tab. lxxvi, fig. 156.

Flavo brunneus vel rufescens, subtus pallidior, capite cum lamina prima dorsali rubro-castaneo, antennis pedibusque flavis ; minus robustus, sublævis ; capite manifesto marginato, suborbiculari. Antennæ breviusculæ, breviter parcius hirsutæ, 17 articulatæ, articulis ultimis longis vel perlongis.

Metameri quarti prosterni margo anterior medius manifesto callosus, leviter productus, subrectus vel obscure sinuatus.

Pedes anales glabri, longi, spina inferiore magna, interiore parva.

Laminæ dorsales præter priores in lateribus manifesto marginatæ.

Pleuræ posticæ scabrosæ, poris majoribus atque minoribus, numerosis perforatæ, in spinam robustiorem, breviorem productæ.

Lamina ultima ventralis latiuscula, valde angustata, post subrecta. Long. $65 \mathrm{~mm}$.

Having compared typical specimens, both of the Sc. sexspinosus and of the Sc. spinicauda Wood, I cannot perceive any true or specific difference between them.

This species is very common and spread over the greater part of North America; I have seen specimens, preserved in the Museum of Comp. Zoöl., from Frederick county, Md., P. R. Uhler; Massachusetts, Miss A. M. Edmands, Cambridge, Mass.; Berkshire, Tioga county, N. Y.; Centre county, Pa., Shaler; Virginia, Crandall ; Pennington's Gap, Lee county, Va.; Rosswell, Ga., Mr. King; Yellow Springs, Ohio; Rocky creek, Grayson county, Ky., F. W. Putnam; Macgregor, Iowa, Davis ; Ritchie county, W. Va., N. E. Ingersen; San Mateo, Cal., A. Agassiz (Sc. spinieauda, the type of Mr. Wood).

\section{Scolopocryptops Georgices, n. sp.}

Fulvus, capite rufescente, pedibus flavis ; gracilis, sublævis, capite obscure marginato, subovato. Antennæ subglabræ, breves vel breviusculæ, 17-articulatæ, articulis prioribus transversalibus, anterioribus breviusculis.

Metameri quarti prosterni margo medius obscure callosus, productus, in angulum incisus, dentibus duobus armatus.

Pedes anales glabri, breviusculi, spina inferiore maxima, interiore parva vel perparva.

Laminæ dorsales præter sex priores marginatæ.

Pleuræ posticæ sublæves, integræ, magnam partem obtectæ, in spinam breviorem, acutam productæ.

Lamina ultima ventralis lata, parum angustata, post brevissime sinuata. Long. $35 \mathrm{~mm}$.

Hab. Georgia; I have seen two specimens. 


\section{Scolopocryptops Miersir.}

Scolopocryptops Miersii Newport, Trans. Linn. Soc. Lond., xix, p. 405.

Gervais, Walckenaer Ins, Apt., iv, p. 298.

? Scolopocryptops melanostoma Newport, Trans. Linn. Soc. Lond., xix, p. 406.

? Scolopocryptops melanosoma Gervais, Walckenaer Ins. Apt., iv, p. 298.

Scolopocryptops sexspinosus p.p. Kohlrausch, Arch. f. Naturg. Jahrg., 47, p. 54 .

Castaneus, subtus fulvus, antennis pedibusque flavis, posterioribus sæpe majorem vel maximam partem cœruleis ; robustus, sublævis, capite vix marginato, orbiculari. Antennæ longiusculæ, longius, dense hirsutæ, 17articulatæ, articulis omnibus longis.

Metameri quarti prosterni margo anterior medius valde callosus, productus, manifesto sinuatus, sinu dentibus duobus majoribus vel minoribus armatus.

Pedes anales longi vel perlongi (maris? manifesto pilosi), spina inferiore maxima, interiore majore vel minore.

Laminæ dorsales præter sex priores atque duas posteriores vel saltem ultimam immarginatæ.

Pleuræ posticæ scabrosæ atque porosæ, in spinam longam, acutam (vel maris? longissimam, acutissimam) productæ.

Lamina ultima ventralis perlata, manifesto angustata, post sat profunde sinuata.

Long. $70 \mathrm{~mm}$.

$H a b$. This species seems to prefer the more southern parts of North America, and I have also seen other specimens from the larger Islands of West India; from Jeremie, Hayti, Dr. D. F. Wienland; Grande Anse, Hayti, Uhler; Kingston, Jamaica, Garman; Monn (?) Rouge, Martinique, Garman. It is also found in South America.

\section{Segmenta pedifera 21.}

A. Segmentum septimum spiraculis instructum.

\section{Gen. Heterostoma.}

1. Heterostoma trigonopoda.

Scolopendra trigonopoda Leach, Zool. Miscell., iii, p. 36.

Heterostoma trigonopoda Newport, Trans. Linn. Soc. Lond., xix, p. 413.

?. Heterostoma sulcidens Kohlrausch, Arch. f. Naturg. Jahrg., 47, p. 59, tab. iv, figs. 5-7.

One specimen of this genus, from Monrovia in Africa, is re- 
ferred by me to the above named species; but the specimen is so badly preserved, that no further or closer investigations have been possible either of the characters of the genus or of those of the species.

\section{Gen. Branchiostoma.}

Branchiostoma Newport, Trans. Linn. Soc. Lond., xix, p. 411.

Lamina cephalica a lamina prima dorsali partim obtecta.

Oculi ocellis 4 .

Antennæ longiusculæ, tenuiusculæ, manifesto attenuatæ, 18-21-articulatæ.

Labri fimbria brevis, setis simplicibus.

Labii processus subconici, barba e setis brevibus, densis, uncinatis facta; palporum fimbria e setis brevibus, densis, uncinatis facta.

Palporum maxillarium unguis in latere interiore dentibus binis longis, acutis armatus; fimbria digitalis setis parum uncinatis, unguem nullo modo explens.

Mandibulæ ante pectinibus $10-12$ juxta et pone lamellam dentatam coarctatis instructæ.

Metameri quarti sternum integrum, sat robustum; prosternum longe prominens, ante in dentes majores incisum; pedes prensorii articulo secundo et tertio minimis, interruptis.

Segmentum septimum spiraculis instructum.

Spiracula sat profunda, magna, subovalia vel post subtriangula, fere perpendicularia ; antica abrupte majora minusque profunda.

Pleuræ posticæ infra porosæ. in spinam longam productæ.

Pedes anales elongati, quinquearticulati, articulo primo (femore) spinigero vel inermi, ungue minus curvato, subgracili ad basin unguiculis binis longioribus, rectis armato.

\section{Branchiostoma affine.}

Branchiostoma affine Kohlrausch, Beit. z. Kenntn. d. Sc., p. 22.

$$
\text { Arch. f. Naturg. Jahrg., 47, p. } 68 .
$$

Fusco-griseum vel flavum, in dorso medio linea angusta, pallida notatum, pedibus antennisque flavis; sat gracile, manifesto sparse punctatum, laminis ventralibus integris, capite subovali, immarginato. Antennæ breviusculæ, 18.articulatæ, præter articulos ternos priores dense, brevissime hirsutæ, articulis mediis longiusculis.

Dentes prosternales quaterni, obtusi, per paria approximati, exteriores minores vel evanidi ; dens coxalis obsolete trilaciniatus.

Pedes anales perlongi, graciles, in latere interiore femoris spinis parvis 3-5 in seriem singulam, in latere inferiore spinis 4-7 in series binas digestis armati.

Laminæ dorsales quatuor priores omnino, 5-7 fere immarginatæ, ceteræ manifesto marginatæ. 
Pleuræ posticæ sublæves, porosæ, in angulum longe productum, spinis ternis parvis armatum desinentes, in latere postico obliquo spina singula armatæ.

Lamina ultima ventralis angustiuscula, rotundate angustata, post manifesto sinuata.

Long. $62 \mathrm{~mm}$.

Hab. Pegu, Burmah, C. H. Carpenter; 70 miles from Ambala, E. India, Mr. Carleton; Mauritius, Mr. Pike; Zanzibar, Mr. C. Cooke; ard also Basseterre, St. Cristophori.

\section{Branchiostoma celer.}

Branchiostoma celer Humbert et Saussure, Rev. et Mag. Zoöl., 2 ser., xxii, p. 202.

Saussure et Humbert, Etud. s. Myriap., p. 122, tab. vi, fig. 16 , etc.

Kohlrausch, Arch. f. Naturg. Jahrg., 47, p. 69.

Viride vel viridi-olivaceum, subtus flavo-brunneum vel ochraceum, pedibus præter posteriores antennisque præter articulos ternos priores vel totis flavo-brunneis; sat gracile vel robustius, sublæve, capite suborbiculari, immarginato, margine postico plus vel minus obtecto. Antennæ breviusculæ, 20-(18-21-)articulatæ, præter articulos ternos priores dense, breviter hirsutæ, articulis mediis longis vel longiusculis.

Dentes prosternales quaterni, per paria paulum approximati, obtusiusculi ; dens coxalis sublævis.

Pedes anales perlongi, graciles, inermes.

Laminæ dorsales præter quatuor priores marginatæ.

Pleuræ posticæ manifesto scabrosæ, dense porosæ, in angulum lævem, acutum, spinis binis armatum productæ.

Lamina ultima ventralis latiuscula, rotundate angustata, post manifesto sinuata.

Long. $70 \mathrm{~mm}$.

Hab. Kingston, Jamaica, Mr. Garman; Polvon, Occidental Dept. Nicaragua, Mr. McNiel.

B. Segmentum septimum absque spiraculis.

\section{Gen. Otostigma.}

Otostigmus Porath, Sv. Vet. Akad. Handl. Bih., B. 4, p. 18.

Branchiotrema Kohlrausch, Beitr. z. Kenntn. d. Scol., p. 22.

Arch. f. Naturg. Jahrg., 47, p. 70.

Lamina cephalica a lamina prima dorsali partim objecta.

Oculi ocellis 4 . 
Antennæ longiusculæ, crassiusculæ, manifesto attenuatæ ; 18-23-articulatæ.

Labri fimbria brevis, setis paucioribus, simplicibus.

Labii processus subteretes, barba e setis brevibus, densis, uncinatis facta ; palporum fimbria e setis brevibus, densis, uncinatis facta.

Palporum maxillarium unguis in latere interiore dente singulo, longo, acuto armatus ; fimbria digitalis setis parum uncinatis, unguem superans.

Mandibulæ ante 10-12 juxta et pone lamellam dentatam coarctatis instructæ.

Metameri quarti sternum integrum, robustum; prosternum longe prominens, ante in dentes magnos incisum ; pedes prensorii articulo secundo et tertio minimis, interruptis.

Segmentum septimum absque spiraculis.

Spiracula sat profunda, magna, subovalia vel post subrotunda, obliqua, per paria sensim magis perpendicularia, antica abrupte majora minusque profunda.

Pleuræ posticæ infra porosæ, in spinam longam post productæ; vel truncatæ.

Pedes anales elongati vel valde elongati, quinquearticulati, articulo primo (femore) spinigero vel inermi, ungue minus curvato, subgracili, ad basin unguiculis binis parvis, subrectis armato.

\section{Otostigma Luzonicum.}

Branchiotrema Luzonicum, calcitrans, ?astenon Kohlrausch, Beitr. z. Kenntn, d. Scol., p. 23.

Arch. f. Naturg. Jahrg., 47, p. 73 and 72.

Ochraceum, plus vel minus olivaceum, antennis pedibusque flavescentibus; subgracile vel gracile, laminis dorsalibus sulcis pluribus plus vel minus manifestis exaratis, laminis ventralibus ad latera profunde bisulcatis, in medio obscure bifoveolatis vel sulcatis ; capite subovali, post truncato. Antennæ longiusculæ, ad basin paulum incrassatæ, 18-articulatæ, præter articulos binos vel ternos priores manifesto hirsutæ articulis breviusculis vel brevibus.

Dentes prosternales quaterni majores, per paria approximati (exteriore sæpe evanidi); dens coxalis in latere carinatus.

Pedes anales longi, graciles, teretes, in margine sup. interiore femoris spinis binis minoribus, uniseriatis, angulo apicali evanido spina singula minore instructo, in latere interiore spinis ternis minoribus, uniseriatis, in margine inf. interiore spinulis binis majoribus uniseriatus, in margine exter. inferiore spinulis ternis majorıbus uniseriatis armati.

Laminæ dorsales præter sex priores marginatæ.

Pleuræ posticæ sat amplæ, compressiusculæ, sublæres, sparsius, grossius porosæ, in angulum longum, trifidum, in latere superiore spinula parva singula, in latere exteriore interdum spinula parva instructum pro- 
ductæ, margine postico in obliquum levissime sinuato, spinula minore armato.

Lamina ultima ventralis latiuscula, lateribus rotundatis, valde convergentibus, post manifesto sinuata.

Long. $45 \mathrm{~mm}$.

Hab. Koolloo Valley, East India, Mr. Carleton (4 spec.).

\section{Otostigma carinatum.}

Otostigmus carinatus Porath, Sv. Vet. Akad. Handl. Bih. B. 4, p. 20. Branchiotrema multicarinatum Kohlrausch, Beitr. z. Kenntn. d. Scol., p. 22 , fig. 5 .

Arch. f. Naturg. Jahrg., 47, p. 71, tab. v, fig. 12.

Ochraceum vel fusco-griseum, capite cum lamina prima atque ultima dorsali brunneo; subgracile, laminis dorsalibus prioribus (2-7) sublævibus, mediis atque posterioribus plus vel minus manifesto septemcarinatis, ad latera rugulosis, laminis ventralibus obscure bisulcatis, capite subcordiforme, lateribus manifesto marginatis, post truncato. Antennæ longiusculæ, ad basin paulum incrassatæ, 20-23-articulatæ, præter articulos binos vel ternos priores hirsutæ, articulis pluribus vel omnibus breviusculis vel brevibus.

Dentes prosternales quaterni, majores, per paria approximati; dens coxalis in latere nodulis ternis parvis instructus.

Pedes anales perlongi, pergraciles, in margine sup. interiore femoris spinulis minutis, sæpissime ternis, angulo apicali non producto spinula singula minuta instructo, in latere interiore spinulis $2-6$ minutis, in series binas digestis, in latere inferiore spinulis 4-8 parvis, in series binas digestis armati.

Laminæ dorsales præter quatuor vel sex priores marginatæ.

Pleuræ posticæ sat amplæ, compressiusculæ, densius, grossius porosæ, in angulum longum, ad apicem spinulis ternis vel quaternis minoribus instructum productæ, margine postico in obliquum subtruncato, spinulis binis minoribus armato; anguli pleurarum plus vel minus approximati.

Lamina ultima ventralis latiuscula, lateribus valde rotundatis, valde convergibus, post manifesto sinuata.

Long. $66 \mathrm{~mm}$.

Hab. Shanghai, Mrs. A. P. Chamberlain.

\section{Otostigma occidentale, n. sp.}

Ochraceum, ante et post plus vel minus virescens, linea media dorsali angusta pallida; subgracile, ante sublæve, post manifesto hirsutum, in lateribus rugulosum, laminis ventralibus sublævibus; capite subcordiforme, post truncato. Antennæ longiusculæ, ad basin paulum incrassatæ,

PROC. AMER. PHILOS SOC. XXIII. 122. X. PRINTED DECEMBÉ 16, 1885. 
21-articulatæ, præter articulos binos vel ternos priores manifesto hirsutæ, articulis breviusculis.

Dentes prosternales terni vel quaterni minores, acutiusculi ; dens coxalis acutiusculus, simplex.

Pedes anales longiusculi, vix incrassati, articulis binis prioribus vix clavatis, femore inermi, post restricto.

Laminæ dorsales præter $12-13$ priores marginatæ.

Pleuræ posticæ amplæ, sparse grossius porosæ, area antica glabra, majore, angulo apicali nullo, margine postico leviter arcuato.

Lamina ultima ventralis angustiuscula, lateribus rotundatis, valde convergentibus, post obscure sinuata.

Long. $45 \mathrm{~mm}$.

The spiracles of this species are much smaller than the spiracles of most other species of the genus; yet, as to their construction, they all conform with the scape which ordinarily is found in Otostigma. Also with regard to the pedes anales and to the pleuræ, this is not a little different from the two others here described, perhaps, a new genus ought to be formed.

Hab. Grande Anse, Hayti, Mr. Uhler.

\section{Gen. Cupipes.}

Cupipes Kohlrausch, Beitr. z. Kenntn. d. Scol., p. 23.

Arch. f. Naturg. Jahrg., 47, p. 78.

Lamina cephalica a lamina prima dorsali partim obtecta ; scuta dorsalia metameri tertii manifesta.

Oculi ocellis 4.

Antennæ breviusculæ, crassiusculæ, manifesto attenuatæ, 17-articulatæ.

Labri fimbria longa, setis paucioribus, simplicibus.

Labii processus subteretes, barba e setis brevibus, densis, uncinatis facta; palporum fimbria e setis brevibus, densis, uncinatis facta.

Palporum maxillarium unguis in latere interiore dentibus binis longis, acutis armatus ; fimbria digitalis, setis uncinatis, ad apicem dentatis, unguem longe superans.

Mandibulæ ante 13 pectinibus juxta et pone lamellam dentatam coarctatis instructæ.

Metameri quarti sternum integrum, minus robustum ; prosternum longe prominens, ante in dentes magnos incisum; pedes prensorii articulo secundo et tertio parvis, interruptis.

Segmentum septimum absque spiraculis.

Spiracula profunda vel sat profunda, parva vèl minima, subtriangula, priora longitudinalia, posteriora per paria sensim brevius triangula vel rotundata, minus profunda, magnitudine decrescentia.

Pleuræ posticæ infra porosæ, truncatæ.

Pedes anales breves vel perbreves, deplanati, quinquearticulati, articulo 
primo (femore) spinigero, ungue crasso, parum arcuato, absque unguiculis, infra carina longa, densissime crenulata instructo.

\section{Cupipes ungulatis, n. sp.}

? ? Cormocephalus Brasiliensis Humbert et Saussure, Rev. et Mag. Zool., 2 ser., xxii, p. 203.

Etud. s. Myriap., p. 124, tab. vi, fig. 17, etc.

Flavus, ante et post fulvescens ; sat gracilis, sparse, brevissime hirsutus, laminis dorsalibus posteribus præter sulcos ordinarios sulcis binis obsoletis, laminis ventralibus sulcis binis profundis exaratis; capite subovali, immarginato, obsolete longitudinaliter bisulcato, post in transversum arcuato, sulcato. Antennæ breviusculæ, tenuiusculæ, paulum attenuatæ, 17-articulatæ, præter articulos senos vel octonos priores dense, breviter hirsutæ, articulis breviusculis, subteretibus.

Dentes prosternales bini (interiores bifidi vel trifidi, exteriores minores, acuti); dens coxalis sat magnus, acutiusculus, nodulis binis in latere armatus.

Pedes anales breves vel perbreves, percrassi, fere contigui, in latere sup. interiore femoris spinulis ternis parvis, in seriem arcuatam digestis, in latere interiore spinulis quaternis parvis vel perparvis, in series binas digestis, in latere inter. inferiore spinulis binis parvis vel perparvis, uniseriatis, in latere inferiore sæpe spinulis binis armati ; articulus priore tarsali infra nodo majore instructo.

Laminæ dorsales præter ultimam immarginatæ.

Pleuræ posticæ angustæ, subrugosæ, porosæ, truncatæ, in angulo in teriore spinula perparva, nodiformi armatæ.

Lamina ultima ventralis latiuscula, lateribus rotundatis, manifesto convergentibus, post rotundate truncata.

Long. $40 \mathrm{~mm}$.

Hab. Grande Anse, Hayti, Mr. P. R. Uhler; Port au Prince, Mr. W. Wilson; Pernambuco.

\section{Cupipes quadrisulcatus, n. sp.}

Purpurascente-olivaceus, capite rufescente, pedibus antennisque flavescentibus; minus robustus, laminis dorsalibus medis manifesto quadrisulcatis, anterioribus et posterioribus obsoletius exaratis, laminis ventralibus mediis profunde, anterioribus atque posterioribus obsolete bisulcatis. Antennæ breves, crassæ, attenuatæ, 17-articulatæ, ad apicem obsolete hirsutæ, articulis brevibus vel breviusculis.

Dentes prosternales bini (interiores truncati e ternis confluentes); dens coxalis minus productus, acutiusculus.

Pedes anales perbreves, percrassæ, contiguæ, in margine interiore femoris post spinulis ternis perparvis, in latere sup. interiore spinula singula perparva armati. 
Laminæ dorsales præter undecim priores (obsolete) marginatæ.

Pleuræ posticæ angustæ, subrugosæ, porosæ, rotundate truncatæ.

Lamina ultima ventralis lata, brevis, valde angustata, post rotundate truncata.

Long. $40 \mathrm{~mm}$.

Hab. Ascension Island, South Sea (one single specimen).

6. Gen. Rhoda, n. gen.

Lamina cephalica a lamina prima dorsali partim obtecta.

Oculi ocellis 4 .

Antennæ breviusculæ vel breves, ad basin incrassatæ, valde attenuatæ, 19 -articulatæ, articulis præter ultimum brevibus vel perbrevibus, prioribus transversalibus.

Labri fimbria....

Labii processus....

Palporum maxillarium unguis in latere interiore dentibus binis longisacutis armato ; fimbria digitalis.... unguem medium procul complens.

Mandibulæ....

Metameri quarti sternum integrum, robustum; prosternum perlonge productum, ante in dentes magnos incisum; pedes prensorii articulo secundo et tertio parvis, interruptis.

Segmentum septimum absque spiraculis.

Spiracula profunda, longa, linearia vel paulum triangula, longitudinalia, per paria sensim longitudine paulum decrescentia.

Pleuræ posticæ infra porosæ, truncatæ.

Pedes anales breves vel perbreves, deplanati, quinquearticulati, articulo primo (femore) spinigero, ungue crasso, parum arcuato, absque unguiculis, infra carina longa, densissime crenulata instructo.

As I have had but one single specimen of this new genus to study, I have not been able to give such full characteristics as I wished.

\section{Rhoda Thayeri, n. sp.}

Flava, ante et post paulum fulvescens ; minus gracilis, sublævis, laminis dorsalibus atque ventralibus profunde bisulcatis, capite subovali, immarginato. Antennæ breves, crassæ, 19-articulatæ præter articulos senos priores dense, brevissime hirsutæ, articulis præter ultimum brevibus.

Dentes prosternales terni, validi, truncatæ; dens coxalis productus acutiusculus.

Pedes anales breves, crassæ, contiguæ, in margine sup. interiore femoris spinulis ternis (postica majore, bicuspide) in latere interiore spinulis binis perparvis, in margine inf. interiore spinulis binis parvis armati.

Laminæ dorsales præter ultimam immarginatæ.

Pleuræ posticæ angustæ, subrugosæ, porosæ, truncatæ. 
Lamina ultima ventralis longa, angusta, paulum angustata, post late arcuata.

Long. $58 \mathrm{~mm}$.

Hab. Santarem, Thayer Exped.

7. Gen. Asanada, $n$ gen.

Lamina cephalica libera vel a lamına prima dorsali partim obtecta.

Oculi ocellis 4.

Antennæ perbreves, ad basin incrassatæ, valde attenuatæ, 17-articulatæ, articulis brevibus vel perbrevibus, prioribus transversalibus.

Labri fimbria brevis, maxime obtecta, setis paucioribus simplicibus.

Labii processus breves, subconici, barba evanida; palporum fimbria e setis perbrevibus, sparsis, uncinatis facta.

Palporum maxillarium unguis simplex; fimbria digitalis brevis, setis paucioribus, uncinatis, ad apicem dentatis, unguem medium procul complens.

Mandibulæ ante 12 pectinibus juxta et pone lamellam dentatam coarctatis instructæ.

Metameri quarti sternum in medio canaliculatum, robustum; prosterLum longe prominens, ante in dentes majores incisum; pedes prensorii articulo secundo et tertio perparvis, interruptis.

Segmentum septimum absque spiraculis.

Spiracula sat profunda, perparva, producte triangula, longitudinalia, per paria sensim longitudine paulum descrescentia.

Pleuræ posticæ læves, magnam partem obtectæ, truncatæ.

Pedes anales breves, crassi, paulum complanati (mari perbreves, percrassi, deplanati), quinquearticulati, articulo primo (femore) inermi, ungue brevi, crasso, parum arcuato, simplice.

\section{Asanada brevicornis, n. sp.}

Flava vel fulva, subtus pallidior; gracilis, lævis, laminis dorsalibus bisulcatis, anterioribus obsolete, mediis atque posterioribus manifesto, laminis ventralibus manifesto bisulcatis, capite subovato, immarginato. Antennæ perbreves, ad basin incrassatæ, valde attenuatæ, 17-articulatæ, subnudæ, articulis prioribus transversalibus.

Dentes prosternales terni, acuti (mediis maximis) ; dens coxalis parvus, acutiusculus.

Pedes anales breves, crassi, paulum complanati, ad basin distantes (maris perbreves, percrassi, deplanati, supra profundissime sulcati, fere contigui), inermes.

Laminæ dorsales præter ultimam immarginatæ.

Pleuræ posticæ triangulæ, læves, perparvæ, tere obtectæ, truncatæ.

Lamina ultima ventralis lata, brevis, lateribus rotundatis, valde convergentibus, post breviter rotundata.

Long. $35 \mathrm{~mm}$.

Hab. Koolloo, Mr. Carleton. 


\section{Gen. Scolopendra.}

Scolopendra Newport, Trans. Linn. Soc. Lond., xix, p. 377.

Lamina cephalica laminam primam dorsalem partim sæpissime obtegens.

Oculi ocellis 4.

Antennæ plerumque longiusculæ, tenuisculæ, ad basin manifesto incrassatæ, attenuatæ, 17-30-attenuatæ, articulis plerisque longiusculis vel longis.

Labri fimbria longa, setis plus vel minus densis, simplicibus.

Labii processus subconici, barba e setis brevibus, densis, uncinatis facta ; palporum fimbria e setis brevibus, densis, manifesto uncinatis facta.

Palporum maxillarium unguis in latere interiore dentibus binis validis, acutiusculis armatus ; fimbria digitalis brevior, setis longis, densis, parum uncinatis, unguis basin plus vel minus superans.

Mandibulæ ante 10-13 pectinibus juxta et pone lamellam dentatem coarctatis instructæ.

Metameri quarti sternum integrum, robustum; prosternum longe prominens, in dentes majores vel minores incisum; pedes prensorii articulo secundo et tertio parvis, interruptis.

Segmentum septimum absque spiraculis.

Spiracula sat profunda, magna, angusta, post paulum dilatata, longitudinalia, per paria longitudine decrescentia.

Pleuræ posticæ sat amplæ, infra porosæ, post in angulum plus vel minus productum desinentes.

Pedes anales plerumque longiusculi vel longi, rare incrassati, quinquearticulati, articulo primo (femore) sæpissime spinigero, ungue sat magno, minus curvato, ad basin unguiculis binis armato.

Conspectus speciorum :

I. Femora pedium penultimorum (saltem) ad apicem exteriorem spinulis armata.

A. Lamina prima marginem pone dorsalis anticum profunde sulcatum in transversum.

1. Sc. gigas. 2. Sc. cristata. 3. Sc. prasina.

B. Lamina prima dorsalis integra.

4. Sc. alternans. 5. Sc. crudelis.

II. Femora pedum penultimorum ad apicem exteriorem inermia.

A. Lamina prima dorsalis pone marginem anticum in transversum profunde sulcatum.

a. Pedum ultimorum articulus primus tarsalis calcare armatus.

6. Sc. heros. 7. Sc. viridis.

b. Pedum ultimorum articulus primus tarsalis inermis.

8. Sc. occidentalis. 9. Sc. Woodii.

B. Lamina prima dorsalis integra.

a. Pedum omnium articulus primus tarsalis inermis. 
10. Sc. longispina. 11. Sc. Chilensis.

b. Pedum plerorumque articulus primus tarsalis calcare armatus. 12. Sc. morsitans. 13. Sc. rugosa. 14. Sc. subspinipes. 15. Sc. De Haanii. 16. Sc. Indica.

I. Femora pedum penultimorum (saltem) ad apicem exteriorem spinulis armata.

A. Lamina prima dorsalis pone marginem anticum in transversum profunde sulcata.

\section{ScolopendRa gigas.}

Scolopendra gigas Leach, Trans. Linn. Soc. Lond., xi, p. 383.

Newport, Ann. and Mag. of Nat. Hist., xiii, p. 98.

Trans. Linn. Soc. Lond., xix, p. 399.

Kohlrausch, Arch. f. Naturg. Jahrg., 47, p. 119.

Scolopendra insignis Gervais, Ann. Soc. entom. de France, p. xxix.

Walckenaer Ins. Apt., iv, p. 278.

Scolopendra gigantea Porat, Soc. Vet. Akad. Handl. Bih., B. 4, No. 7, p. 5. ? Scolopendra gigantea Linné, Syst. Nat., ed. x, p. 638.

Newport, Trans. Linn. Soc. Lond, xix, p. 400.

Gervais, Walckenaer Ins. Apt., iv, p. 279.

Scolopendra prasinipes, epileptica Wood, Proc. Acad. Nat. Sc. Philad., 1861, p. 11.

Castanea, subtus pallidior, pedibus prioribus in articulis ternis ultimis sæpissime olivaceo balteatis, antennis viridi-olivaceis; valde robustus, sublævis, laminis ventralibus obscure bisulcatis ; capite suborbiculari, immarginato. Antennæ longiusculæ vel longæ, 17-(18-)articulatæ, articulis septenis vel octonis anterioribus dense brevissime gilvo-hirsutæ, articulis præter priores longis.

Dentes prosternales quaterni (bini vel terni interiores maximam partem coaliti), magni; dens coxalis magnus, obtusiusculus, in latere nodulo instructus.

Femora præter prima vel bina priora ad apicem exteriorem spinulis ternis (quinis) armata. Pedum articulus primus tarsalis, pedibus ultimis (analibus) exceptes, calcare armatus.

Pedes anales longiusculi, in latere sup. interiore femoris spinulis majoribus novenis vel duodenis, in series ternas vel quaternas digestis, in angulo exteriore tumido spinulis octonis vel denis, in series binas vel ternas obliquas digestis, in latere inf. interiore spinulis minoribus ternis (binis), in latere inferiore spinulis ternis vel quinis, in series binas digestis, armati.

Laminæ dorsales præter tres vel quatuor priores marginatæ.

Pleuræ posticæ amplæ, sublæves, densissime tenuiter porosæ, in angulum obtusum, spinulis quaternis vel quinis instructum, productæ, margine postico in obliquum fere truncato vel leviter sinuato, inermi. 
Lamina ultima ventralis longa, angusta, lateribus sinuatis manifesto convergentibus, post rotundate truncata vel latissime rotundata.

Long. 220-280 mm.

$H a b$. Santarem, Chas. Linden; Near Santarem, Brazil ; Obidos, Brazil, James \& Hunnewell (Thayer Exped.); Villa Bella, Brazil, J. C. Hetcher.

\section{Scolopendra cristata.}

Scolopendra cristata Newport, Ann. and Mag. of Nat. Hist., xiii, p. 98.

Trans. Linn. Soc., Lond., xix, p. 398.

Porat, Sv. Vet. Akad. Handl. Bih., B. 4, No. 7, p. 6.

Kohlrausch, Arch. f. Naturg. Jahrg., 47, p. 117.

Castanea vel olivacea, antennis pedibusque pallidioribus, concoloribus vel partim balteis olivaceis in articulis omnibus vel exterioribus pedum posteriorum plus vel minus manifestis ornatis, robusta, sublævis ; capite subovali. Antennæ breviusculæ vel longiusculæ, ad basin multum incrassatæ, 17-articulatæ, præter articulos quaternos priores brevissime hirsutæ, articulis præter priores longiusculis vel longis.

Dentes prosternales quaterni (terni interiores plus vel minus coaliti) magni ; dens coxalis in latere nodulo armatus.

Femora terna vel quina posteriora (ante pedes anales) ad apicem exteriorem spinulis binis vel spinula singula armata. Pedum articulus primus tarsalis, pedibus ultimis (analibus) exceptis, calcare armatus.

Pedes anales breviusculi vel breves, incrassati vel crassi, in latere superiore femoris spinulis parvis binis vel spinula singula, in margine sup. interiore spinulis magnis binis vel ternis, angulo apicali in acu forte, acutum, in latere spinulis binis armatum producto, in latere inferiore spinulis senis, in series ternas digestis, armati.

Laminæ dorsales præter quatuor priores marginatæ. Lamina ultima in medio alte carinata.

Pleuræ posticæ sat amplæ, sublæves, densissime tenuiter porosæ, in angulum minorem, ad apicem spinula singula armatum, productæ, margine postico paulum obliquo, subrecto, inermi.

Lamina ultima ventralis breviuscula, angustiuscula, multum angustata, post late rotundata.

Long. 145-175 mm.

Hab. Brazil?, Charles Linden; Amazon river, Brazil, Rev. J. C. Hetcher.

\section{SCOlOpendra PRASINA.}

Scolopendra prasina C. L. Koch, Die Myriap., ii, p. 23, tab. lxxi, fig. 146. Kohlrausch, Arch. f. Naturg. Jahrg., 47, p. 122.

? Scolopendra puncticeps Wood, Proc. Acad. Nat. Sc. Philad., 1861, p. 14. 
?? Scolopendra punctiscuta Wood, Proc. Acad. Nat. Sc. Philad., 1861, p. 14.

Flava vel flavo-brunnea, laminis dorsalibus præter laminam primam et ultimam in margine postico virescentibus, articulis exterioribus pedum posteriorum virescentibus; sat robusta, tenuiter sparse punctata, laminis ventralibus lævibus ; capite suborbiculari. Antennæ breviusculæ ad basin paulum incrassatæ, 17-articulatæ, præter articulos quaternos priores dense gilvo hirsutæ, carinulatæ, articulis breviusculis.

Dentes prosternales quaterni (bini interiores approximati vel coaliti, externi discreti), majores, truncati; dens coxalis in latere nodulo majore instructus.

Femora bina posteriora (ante pedes anales) ad apicem exteriorem spinulis binis, femora antecedentia spinula singula armata. Patellæ binæ posteriores (ante pedes anales) ad apicem exteriorem spinula singula armata. Pedum articulus primus tarsalis, pedibus ultimis (analibus) exceptis, calcare armatus.

Pedes anales breviusculi, sat incrassati, in latere superiore femoris spinulis binis parvis, in margine sup. interiore rotundato spinulis senis majoribus, uncinatis, in margine inf. interiore rotundato spinulis binis minoribus, in latere inferiore spinulis septenis majoribus, in series ternas digestis, armati, in latere interiore articuli sequentis (patellæ) spinulis quaternis minoribus, angulo apicali spinula singula instructo, armati.

Laminæ dorsales præter sex priores marginatæ.

Pleuræ posticæ amplæ, sublæves, densissime tenuiter porosæ, in angulum brevem, spinulis ternis magnis hamatis instructum, productæ, margine postico leviter arcuato, spinula singula armato.

Lamina ultima ventralis breviuscula, latiuscula, multum angustata, post late rotundata.

Long. 90-105 mm.

Hab. Grenada, W. I., Peter Gelliman.

B. Lamina prima dorsalis integra.

\section{Scolopendra alternans.}

Scolopendra alternans Leach, Trans. Linn. Soc., Lond., xi, p. 383.

Scolopendra alternsns, Grayi, complanata, incerta, multispinosa (multispinata) Newport, Trans. Linn. Soc., Lond., xix, p. 402-405.

Scolopendru Sagræa Gervais, Walckenaer Ins. Apt., iv, p. 281.

? Scolopendra torquata Wood, Proc. Acad. Nat. Sc. Philad., 1861, p. 13.

Flavo-brunnea vel præsertim ante et post castanea, margine postico laminarum dorsalium, antennis vel totis vel solummodo in latere inferiore articulorum priorum articulisque pedum exterioribus interdum obscure virescentibus; robusta vel valde robusta, sublævis, laminis ventralibus sat obscure bisulcatis, capite suborbiculari. Antennæ longiusculæ vel PROC. AMER. PHILQS. SOC. XXIII. 122. Y. PRINTED DECEMBEI 31, 188.5, 
longæ, ad basin paulum incrassatæ, attenuatæ, 17-articulatæ, præter articulos quinos priores dense brevissime hirsutæ, carinulatæ, articulis longis.

Dentes prosternales terni (interiores lati, obtusi), validi; dens coxalis magnus, obtusiusculus, in latere interiore nodo vel denticulo obtuso armatus.

Femora pedum penultimorum angulo, spinulis quinis vel senis armato, instructa; pedum antepenultimorum ad apicem exteriorem spinulis binis vel spinula singula armata. Pedum articulus primus tarsalis, pedibus ultimis (analibus) exceptis, calcare armatus.

Pedes anales longiusculi, crassiusculi, in latere superiore femoris spinulis ternis vel senis, majoribus vel minoribus, in series binas subdigestis, in latere sup. interiore spinis quaternis vel senis subseriatis, angulo postico acutiusculo spinis septenis vel octonis instructo, in latere interiore spinis senis vel novenis subseriatis vel in series binas digestis, in latere inferiore spinis septenis vel duodenis, in series ternas digestis, armati.

Laminæ dorsales præter quinque vel septem priores marginatæ.

Pleuræ posticæ minus amplæ, sublæves, densissime tenuissime porosæ, in angulum acutiusculum, spinulis senis vel octonis parvis instructum, productæ, margine postico in obliquum subtruncato, paulum flexuoso, in medio atque ad apicem exteriorem spinulis parvis armato.

Lamina ultima ventralis breviuscula, angustiuscula, valde angustata, post rotundate truncata.

Long. $110-170 \mathrm{~m} . \mathrm{m}$.

$H a b$. This species seems to be a very common one in the West India; yet in the collection of the Museum of Comp. Zoöl, I have found only five specimens, viz: from Cuba, Mr. Trey, and also from Brazil.

5. SCOLOPENDRA CRUDELIS.

Scolopendra crudelis Koch, Syst. d. Myriap. p. 170

Die Myriap., ii, p. 36, tab. lxxvii, lxxviii, fig. 158,159 .

Porat, Sv. Vet. Akad, Handl. Bih., B. 4, No. 7, p. 7. Scolopendra longipes Wood, Journ. Acad. Nat. Sc. Philad., 2 ser., v, p, 26.

Trans. Amer. Philos. Soc., xiii, p. 163.

Castanea vel fulva, antennis pedibusque flavescentibus, margine postico laminarum dorsalium interdum virescente; robusta, sublævis, laminis ventralibus obscure bisulcatis ; capite subovali, immarginato. Antennæ longiusculæ vel longæ, ad basin paulum incrassatæ, attenuatæ, 17-articulatæ, præter articulos quinos priores dense brevissime hirsutæ, carinulatæ, articulis longis, teretibus.

Dentes prosternales quaterni (bini interiores coaliti, truncati), validi; dens coxalis magnus, in latere interiore denticulo majore armatus.

Femora pedum penultimorum angulo spinulis quaternis vel senis in- 
structo, in latere superiore spinulis parvis ternis vel spinula singula armata; pedum antepenultimorum ad apicem exteriorem spinulis binis armata. Pedum articulus primus tarsalis, pedibus ultimis (analibus) exceptis, calcare armatus.

Pedes anales longi, tenuiusculi, in margine sup. interiore femoris rotundato spinulis majoribus sedenis vel vicenis, in series quaternas subdigestis, nodo apicali sat producto, spinulis septenis vel octonis majoribus instructo, in latere inferiore spinulis tredenis vel quatuordenis, in series ternas digestis, armati.

Laminæ dorsales præter septem priores marginatæ.

Pleuræ posticæ minus amplæ, sublæves, densissime tenuissime (poris majoribus intermixtis) porosæ, in angulum majorem, obtusiusculum, spinulis senis instructum productæ, margine postico in obliquum subtruncato, paulum flexuoso, spinulis binis majoribus armato.

Lamina ultima ventralis brevisucula, latiuscula, valde angustata, post rotundate truncata.

Long. $150 \mathrm{~mm}$.

Hab. Florida, Mr. Wurdemann; Double-headed-shot Key (U. S. Coast Survey. Gulf Stream Exped.); Jeremie, Hayti (F. C. Gray's fund).

II. Femora pedum penultimorum ad apicem inermia.

A. Lamina prima dorsalis pone marginem anticum in transversum profunde sulcata.

a. Pedum ultimorum articulus primus tarsalis calcare armatus.

\section{SCOLOPENDRA HEROS.}

Scolopendra heros Girard, Marcy Rep. Explor. Red Riv., p. 272, tab. xviii.

Wood, Trans. Amer. Philos. Soc., xiii, p. 155.

Porat, Sv. Vet. Akad. Handl. Bih., B. 4, No. 7, p. 8.

Scolopendra castaneiceps Wood, Proc. Acad. Nat. Sc. Philad., 1861, p. 11.

Trans. Amer. Philos. Soc., xi:i, tab. i, fig. 7 .

Scolopendra polymorpha Wood, Proc. Acad. Nat. Sc. Philad., 1861, p. 11.

Trans. Amer. Philos. Soc., xiii, p. 158.

Kohlrausch, Arch. f. Naturg. Jahrg., 47, p. 114.

Scolopendra Copeana Wood, Journ. Acad. Nat. Sc. Phil., 2 ser., v, p. 27.

Trans. Amer. Philos. Soc., xiii, p. 165.

? Scolopendra mysteca Humbert et Saussure, Rev. et Mag. Zool., 2 sér., xxi, p. $15 \%$.

Saussure et Humbert, Etud. s. Myriap., p. 130. 
? Scolopendra Azteca, Otomita, Maya, Talteca Saussure, Mém. Mex.Myriap., p. 124-126, tab. 5-6, fig. 41-43, 45 .

Saussure et Humbert, Etud. s. Myriap., p. 128-129, tab. v, fig. $9,10,12,14$.

Brunnea vel flavo-olivacea, capite cum lamina prima dorsali plus vel minus rufescente, pedibus antennisque flavescentibus, margine postico Jaminarum dorsalium sæpe virescente, in medio latius vel manifestus; robusta vel sat robusta, sublævis, laminis ventralibus manifesto bisulcatis; capite suborbiculari, immarginato. Antennæ longiusculæ vel longæ, ad basin paulum incrassatæ, attenuatæ, 24-29 articulatæ, præter articulos senos vel denos brevissime hirsutæ, articulis pluribus anterioribus brevibus vel breviusculis.

Dentes prosternales quaterni (bini vel terni interiores plus vel minus coaliti), majores, obtusi; dens coxalis magnus, acutiusculus, subinermis.

Pedes anales longiusculi vel breviusculi, paulum incrassati, in latere sup. interiore femoris spinulis quaternis vel senis majoribus, in series binas digestis, angulo apicali in nodum longiorem, angustiorem, spinulis ternis vel septenis instructum, producto, in latere interiore spinulis binis vel ternis, in latere inf. interiore spinulis binis vel ternis, in latere inferiore spinulis quaternis vel septenis, in series binas digestis, armati.

Laminæ dorsales præter octo priores marginatæ.

Pleuræ posticæ amplæ, sublæves. dense tenuiter porosæ, in angulum breviorem vel longiorem, obtusiusculum, ad apicem spinulis ternis vel senis instructum, productæ, margine postico sinuato, spinula parva armato.

Lamina ultima ventralis brevis, lata, valde angustata, post subtruncata vel latissime sinuata.

Long. 100-130 mm.

$H a b$. This species seems to be common through the most parts of North and Central America; thus I have seen specimens from Westfield, N. York; near Mammoth Cave, Ky.; Key West; Alexandria, Ga., Anderson; Seabrook Isl., Ga. ; Mobile, Ala.; Springhill, Ala.; Cap Florida, Wurdemann; Galveston, Tex., Boll; Monteviaz, Mex., Palmer ; mountain near St. Louis Potosi, Mex., E. Palmer; Panama; Guatemala, Van Patten; Porto Rico, Cardoge; San Diego, Cal.; Guaymas, Gulf of California; Ft. M'I'herson, Neb.; Riley, Kansas, H. Bravat.

\section{SCOLOPENDRA VIRIDIS.}

Scolopendra viridis Say, Proc. Acad. Nat. Sc. Philad., ii, p. 110.

Wood, Journ. Acad. Nat. Sc. Philad., 2 ser., v, p. 22.

Trans. Amer. Philos. Soc., xiii, p. 159.

Kohlrausch, Arch. f. Naturg. Jahrg., 47, p. 112. 
Scolopendra punctiventris Newport, Ann. and Mag. of Nat. Hist., xiii, p. 100.

Trans. Linn. Soc., Lond., xix, p. 386.

Scolopendra parva Wood, Proc. Acad. Nat. Sc. Philad., 1861, p. 10.

Ochracea vel brunnea, lamina cephalica atque vitta lata dorsali sæpe viridibus ; sat gracilis, manifesto sparse punctata, laminis ventralibus profunde bisulcatis; capite subrotundata. Antennæ longiusculæ, ad basin sat incrassatæ, angustatæ, 23-24 articulatæ, præter articulos senos priores brevissime hirsutæ articulis pluribus brevibus, longioribus interpositis.

Dentes prosternales quaterni (bini interiores fere coaliti, exteriores magis discreti), minores ; dens coxalis sat magnus, obtusiusculus, inermis.

Pedes anales breviusculi, paulum incrassati, in margine sup. interiore femoris rotundato spinulis quaternis majoribus, in series binas digestis, angulo apicali brevissimo, bifido vel spinulis ternis vel quaternis instructo, in latere interiore ante spina singula, in latere inferiore spinulis senis vel octonis, in series quaternas digestis, armati.

Laminæ dorsales præter duodecim vel tredecim priores marginatæ.

Pleuræ posticæ amplæ, dense grossius porosæ, in angulum brevem, spinulis ternis vel quaternis instructum productæ, margine postico leviter sinuato, inermi vel spinula minima armato.

Lamina ultima ventralis longiuscula, angustiuscula, multum angustata, post latissime sinuata.

Long. $60 \mathrm{~mm}$.

Hab. Georgia, A. S. Allanson (an original specimen of this species).

b. Pedum ultimorum articulus primus tarsalis inermis.

\section{SCOlOpendra occidentalis, n. sp.}

Ochracea vel brunnea, laminis dorsalibus præter primam atque altimam plus vel minus virescentibus; subgracilis, sublævis, laminis ventralibus profunde bisulcatis ; capite suborbiculari. Antennæ longiusculæ, ad basin valde incrassatæ, attenuatæ, 23-articulatæ, præter articulos quinos vel senos priores obscure hirsutæ, articulis breviusculis.

Dentes prosternales quaterni (bini interiores approximati), majores ; dens coxalis mediocris, acutus, inermis.

Pedum articulus primus tarsalis, pedibus binis posterioribus exceptis, calcare armatus.

Pedes anales longi, graciles, in margine sup. interiore femoris spinulis quinis vel septenis minoribus, in series binas digestis, angulo apicali vix prominente, spinulis ternis vel quaternis instructo, in latere interiore spinulis ternis parvis, in latere inferiore spinulis quatuordenis vel sedenis, in series ternas digestis, armati.

Laminæ dorsales præter sedecim priores marginatæ.

Pleuræ posticæ angustiusculæ, subrugosæ, sparse tenuiter porosæ, in an- 
gulum longius, ad apicem spinulis quaternis parvis in latere spinula singula instructum, productæ, margine postico leviter sinuato, spinulis binis parvis armato.

Lamina ultima ventralis brevis, lata, valde angustata, post rotundate truncata.

Long. $50 \mathrm{~mm}$.

Hab. West Coast of Mexico, Capt. Goff (a single specimen).

\section{SCOLOPENDRA WOODII.}

Scolopendra incequidens Wood, Trans. Amer. Philos. Soc., xiii, p. 162.

Ochracea vel brunnea, antennis laminisque dorsalibus præter primam atque ultimam sæpe olivaceis vel virescentibus, linea media dorsali pallida, obscure marginata; subgracilis, sublævis, laminis ventralibus profunde bisulcatis; capite subovali. Antennæ breviusculæ, ad basin paulum incrassatæ, 17-articulatæ, præter articulos octonos priores manifesto hirsutæ, articulis brevibus.

Dentes prosternales quaterni (bini interiores plus vel minus coaliti), minores; dens coxalis mediocris, ad apicem obscure carinatus.

Pedum omnium articulus primus tarsalis inermis.

Pedes anales breviusculi, sat incrassati, in margine sup. interiore femoris spinulis quinis majoribus, in series binas digestis, angulo apicali in spinam acutum, breviorem, simplicem vel bifidum producto, in latere inferiore spinulis senis vel septenis magnis, in series ternas digestis, armati.

Laminæ dorsales modo tres vel quatuor posteriores marginatæ.

Pleuræ posticæ sat amplæ, rugosæ, sparsius grossius porosæ, in angulum longum, angustum, ad apicem spinis binis vel quaternis instructum productæ, margine postico in obliquum profunde sinuato, inermi.

Lamina ultima ventralis breviuscula, latiuscula, valde angustata, post latissime sinuata.

Long. $60 \mathrm{~mm}$.

Mr. Wood has determined this species as Sc. inæquidens Gervais, but I do not believe that this determination is right, and although the description of Gervais is very incomplete or incertain, yet his original specimen is said to exist in the museum at Paris, and so we may be sure that at some time this same specimen will be more completely described, and then Gervais' name will be attached to another species and not to that of which I am here treating. Therefore it might be better to alter the name at this time, and so I propose the name of Sicolopendra Woodii in honor of Dr. Wood, the first man who has made it clear how much the species of Scolopendra vary in the greater part of the characters, which we have been accustomed to believe to be the most characteristic. 
Hab. Hilton Head, S. C., Dr. Greene; Beaufort, N. C., J. G. Shute; Pennington's Gap, Lee Co., Va.; I have seen specimens besides from Massachusetts, and other places in the United States.

B. Lamina prima dorsalis integra.

a. Pedum omnium articulus primus tarsalis inermis.

\section{Scolopendra longispina, n. sp.}

Ochracea vel brunnea, supra plus vel minus olivacea, linea media dorsali angusta pallida; subgracilis, sublævis, laminis ventralibus manifesto bisulcatis; capite subovali. Antennæ breviusculæ, ad basin sat incrassatæ, 17-19-articulatæ, præter articulos quaternos vel quinos priores brevissime hirsutæ, articulis breviusculis.

Dentes prosternales quaterni (bini interiores approximati vel coaliti), majores; dens coxalis in latere nodulis binis vel nodulo singulo armatus.

Pedes anales breviusculi, plus vel minus incrassati, in margine sup. interiore femoris supra fere planiusculi spinulis ternis vel quinis majoribus vel magnis, in series binas digestis, angulo apicali in spinam longiorem, bi- vel quadrifidam producto, in latere interiore spinulis quaternes vel septenis majoribus, in series binas digestis, in latere inferiore spinulis septenis vel novenis majoribus, in series binas digestis, ad basin spinulis ternis vel quinis, in seriem obliquam digestis, armati.

Laminæ dorsales modo tres vel sex posteriores marginatæ.

Pleuræ posticæ sat amplæ, subrugosæ, densius grossius porosæ, in angulum longum, angustum, ad apicem spinulis quaternis vel quinis, in latere superiore spinulis binis vel quaternis, in latere exteriore spinulis binis vel spinula singula instructum productæ, margine postico subtruncato, spinula singula minore armato.

Lamina ultima ventralis brevis, perlata, valde angustata, post late rotundata.

Long. $60 \mathrm{~mm}$.'

Hab. Maldonado, Brazil, Mr. T. G. Carey.

\section{Scolopendra Chilensis.}

? Scolopendra Chilensis Gervais, Walckenaer Ins. Apt., iv, p. 285.

Ochracea, plus vel minus olivacea, pedibus pallidioribus ; gracilis, sublævis, laminis ventralibus leviter vel obscure bisulcatis; capite subovali. Antennæ longiusculæ, ad basin paulum incrassatæ, 17-18-articulatæ, præter articulos senos priores breviter hirsutæ, articulis præter priores longiusculis.

Dentes prosternales quaterni (bini interiores approximati), minores; dens coxalis mediocris, simplex.

Pedes anales longi vel elongati, graciles, teretes, in latere interiore 
femoris spinulis undenis minoribus, in series ternas digestis, angulo apicali in spinam brevem, bifidam producto, in latere inferiore ad marginem exteriorem spinulis undenis minoribus, in series binas digestis, armati.

Laminæ dorsales modo quatuor vel sex posteriores marginatæ.

Pleuræ posticæ amplæ, subrugosæ, sparsius tenuiter porosæ, in angulum longum, angustam, subteretem, ad apicem spinulis quinque in latere exteriore spinulis binis instructum productæ, margine postico in obliquum subtruncato, spinula singula parva armato.

Lamina ultima ventralis brevis, perlata, valde angustata, post brevius rotundata.

Long. $50 \mathrm{~mm}$.

Dr. Kohlrausch, l. c., p. 125, has suggested that the Sc. Chilensis of Gervais may be a Cormocephalus ; in reality the present species very nearly approaches that genus, but the structure of the lamina cephalica does not permit such a reference.

Hab. Zalcuhana, Chili, Hassler Exped.; Cordova, Argent., Mr. Davis.

b. Pedum plerorumque articulus primus tarsalis calcare armatus.

\section{SCOLOPENDRA MORSITANS.}

Scolopendra morsitans Kohlrausch, Arch. f. Naturg. Jahrg., 47, p. 104.

Scolopenara morsitans, angulipes, ? varia, platypoides, tigrina, Leachii, angusta, formosa, longicornis, tuberculidens, Fabricii, ? Richardsonii, Algerina Newport, Trans. Linn. Soc., Lond., xix, p. 378-387.

Scolopendra Gervaisiana, Scopoliana, fulvipes, elegans, erythrocephala, bilineata,? Togana, platypus Gervais, Walckenaer Ins. Apt., iv, p. 259-280.

Scolopendra carinipes, Californica Saussure et Humbert, Etud. s. Myriap., p. $125-127$, tab. v, fig. 6 and 8 .

Scolopendra pella, porphyratcenia Wood, Proc. Acad. Nat. Sc. Philad., 1861, p. 13-15.

Scolopendra morsitans Wood, Trans. Amer. Philos. Soc., xiii, p. 161.

Scolopendra morsitans, ? Scopoliana, Gervaisiana, planipes, infesta C. L. Koch, Die Myriap., i, fig. 33, 34, 46 ; ii, figs. 179, 180.

Scolopendra picturata, intermedia, cognata, Alfzelii, Leachii, attenuata, pilosella, chorocephala, Wallbergi, saltatoria Porath, Ofvers. Vet. Akad. Förh., 18శ1, No. 9, p. 1144-1151.

Scolopendra platypus, longicornis, cognata, impressa Porat, Sv. Vet. Akad. Handl. Bih., B. 4, No. 7, p. 11-13.

Scolopendra Mossambica, ? brachypoda Peters, Reís. Mozamb. Zool., v, p. 527-529, tab. xxxiii, figs. 1-2. 
Ochracea vel brunnea, sæpe plus vel minus olivacea, margine postico laminarum dorsalum sæpissime, antennis pedibus posterioribus partim pleurisque sæpe virescentibus; robusta vel minus robusta, sublævis, laminis ventralibus plus vel minus manifesto bisulcatis; capite subovali. Antennæ longiusculæ, ad basin paulum incrassatæ, attenuatæ, 17-22 articulatæ, præter articulos senos vel septenos priores brevissime hirsutæ, articulis mediis longiusculis.

Dentes prosternales quini vel rare quaterni (bini vel terni interiores plus vel minus coaliti), minores, obtusiusculi; dens coxalis in latere nodulo parvo armatus.

Pedum articulus primus tarsalis, pedibus ultimis vel binis posterioribus exceptis, calcare armatus.

Pedes anales breviusculi, plus vel minus incrassati (varissime longiusculi, vix incrassati), articulis binis prioribus deplanatis marginatis, in margine sup. interiore femoris spinulis quaternis vel quinis longis, in series binas digestis, angulo apicali in spinam longiorem, tri- vel quadrifidam producto, in latere inferiore spinulis senis vel novenis majoribus, in series ternas concinne digestis, armati.

Laminæ dorsales posteriores marginatæ.

Pleuræ posticæ latæ, sublæves, dense porosæ, in angulum minorem, trivel quadrifidum productæ, margine postico fere in transversum leviter sinuato, spinula perparva armato.

Lamina ultima ventralis breviuscula, latiuscula, lateribus sinuatis, valde angustata, post brevius rotundata.

Long. 90-130 mm.

Perhaps this Scolopendra is the most inconstant species among all the Myriapods, but also very few animals are so common and so widely distributed as Sc. morsitans; yet through all its variations the short, flat, marginated pedes anales with three rows of larger spines on the under side of the femora seldom are missed. On the other hand, if we are not willing to believe in such variability, we are compelled to accept an infinity of species, such as most conspicuously v. Porat has made; but I do not hesitate to say that a larger number of specimens from different parts of the world will bring us to follow the views which Dr. Wood and Dr. Kohlrausch have so forcibly declared with regard to the genus Scolopendra.

$H a b$. This species is found in all tropical regions, whence it is often brought alive in ships to more northern localities. For this reason it will be of no value to enumerate all those from which specimens have been received by the Museum.

PROC. AMER. PHILOS. SOC. XXIII. 122. Z. PRINTED DECEMBER 31, 1885. 


\section{Scolopendra Rugosa, n. sp.}

Rufo-brunnea, pedibus antennisque flavis; minus robusta, manifesto rugosa ; capite subcordiformi. Antennæ longiusculæ, ad basin valde incrassatæ, 18-articulatæ, præter articulos senos vel septenos priores brevis. sime hirsutæ, articulis breviusculis.

Dentes prosternales seni (bini interiores approximati), parvi; dens coxalis ad apicem carinatus, in latere nodulo instructus.

Pedum articulus primus dorsalis, pedibus binis posterioribus exceptis, calcare armatus.

Pedes anales breviusculi, incrassati, in margine sup. interiore rotundato femoris spinulis ternis magnis, in trigonum digestis, angulo apicali in spinam breviorem, acutam, bifidam producto, in latere inferiore spinis binis magnis seriatis, armati.

Laminæ dorsales præter septem priores marginatæ.

Pleuræ posticæ amplæ, sublæves, densissime porosæ, in angulum minorem, bifidum productæ, margine postico in obliquum leviter arcuato, inermi.

Lamina ultima ventralis longiuscula, latiuscula, valde angustata, post manifesto sinuata.

Long. $120 \mathrm{~mm}$.

Hab. Hong-Kong, Capt. W. H. A. Putnam (one single specimen).

\section{Scolopendra subspinipes.}

Scolependra subspinipes Kohlrausch, Arch. f. Naturg. Jahrg., 47, p. 96. ? Scolopendra subspinipes Leach, Trans. Linn. Soc. Lond., xi, p. 383.

Scolopendra subspinipe*, Placea, ? Gervaisii, ? Ceylonensis, planiceps, sexspinosa, lutea, ornata, flava Newport, Trans. Linn. Soc. Lond., xix, p. 389-392.

Scolopendra subspinipes, Lucasii, rarispina, Sandwoichiana, audax, ? Neroportii Gervais, Walckenaer Ins. Apt., iv, p. 262-281.

Scolopendra byssina, dinodon, parvidens, atra, plumbeolata Wood, Proc. Acad. Nat. Sc. Philad., 1861, p. 10-14.

Scolopendra byssina Wood, Trans. Amer. Philos. Soc., xiii, p. 164.

Scolopendra pulchra, mactans, ferruginea, sulphurea, gigantea, ornata G. L. Koch, Die Myriap., i, figs. 21, 79, 80, 92 ; ii, figs. 133, 134.

Scolopendra elongata Porath, Ofvers. Vet. Akad. Förh., 1871, No. 9, p. 1143.

Ochracea vel brunnea, præter caput laminamque primam dorsalem plus vel minus olivacea, margine postico laminarum dorsalium sæpe virescente; robusta vel valde robusta, læviuscula, laminis ventralibus obscurius bisulcatis ; capite suborbiculari. Antennæ longiusculæ, ad basin paulum incrassatæ, attenuatæ, 17-20-articulatæ, præter senos priores hirsutæ, articulis plurimis longis. 
Dentes prosternales quini vel seni, rarissime quaterni vel septeni, minores, obtusiusculi ; dens coxalis magnus, ad apicem carinatus, in latere nodulo parvo instructus.

Pedum articulus primus tarsalis, pedibus ultimis vel binis posterioribus exceptis, calcare armatus.

Pedes anales longiusculi, sat graciles, in margine sup. interiore rotundato femoris paulum deplanati spinulis sæpissime binis majoribus, angulo apicali plus vel minus producto sæpissime bifido, in latere interiore spinula singula vel nulla, in latere inferiore spinulis binis, in seriem longitudina. lem digestis, armati.

Laminæ dorsales præter quatuor vel quinque priores marginatæ.

Pleuræ posticæ minus amplæ, subrugosæ, densissime porosæ, in angulum minorem, bifidum productæ, margine postico leviter arcuato, inermi.

Lamina ultima ventralis longiuscula, angustiuscula, valde angustata, post brevius rotundata.

Long. $150-180 \mathrm{~mm}$.

With regard to frequency, distribution and variability Sc. subspinipes comes near to Sc. morsitans, and therefore I can here refer to my preceding remarks.

Hab. This species also is so common in all tropical and subtropical localities, that I shall not enumerate the many places from which the Museum has specimens.

15. Scolopendra De HaAnir.

Scolopendra De Haanii Brandt, Recueil, p. 59.

Kohlrausch, Arch. f. Naturg. Jahrg., 47, p.

Scolopendra Sithetensis, ? inermis, ?concolor, Childreni, Hardwickii Newport, Trans. Linn. Soc. Lond., xix, p. 393-395.

Scolopendra ?limicolor, ? cephalica, ??gracilis (var.) Wood, Proc. Acad. Nat. Sc. Philad., 1861, p. 12-13.

Scolopendra bispinipes Wood, Trans. Amer. Philos. Soc., xiii, p. 166.

Scolopendra bicolor Humbert, Essai Myriap. Ceylan, p. 12.

Scolopendra histrionica, horrida C. L. Koch, Die Myriap., i, figs. 44, 67.

Scolopendra fissispina C. L. Koch, Verh. Zool. bot. Ges. z. Wien, xv, p. 891.

Flavo-brunnea, supra sæpe, præsertim in margine postico laminarum dorsalium, olivacea vel virescens (interdum laminis dorsalibus alternantibus totis olivaceis) ; robusta vel valde robusta, sublævis, laminis ventralibus manifesto bisulcatis ; capite suborbiculari. Antennæ longiusculæ, ad basin valde incrassatæ, attenuatæ, 18-articulatæ, præter articulos senos priores densissime brevissime hirsutæ, articulis plerisque longis.

Dentes prosternales quini, rare quaterni, minores, obtusi; dens coxalis magnus, obtusiusculus, nodo vel nodis obsoletis instructus. 
Pedum articulus primus tarsalis, pedibus binis posterioribus exceptis, calcare armatus.

Pedes anales longiusculi vel longi, sat graciles, in margine sup. interiore femoris paulum vel sat deplanati spinulis binis tenuibus, interdum evanidis, angulo apicali in spinam longam angustatam, sæpissime bifidam producto, armati.

Laminæ dorsales præter sex vel undecim priores marginatæ.

Pleuræ posticæ amplæ, sublæves, densissime tenuius porosæ, in angulum majorem, bifidum productæ, margine postico in obliquum leviter arcuato, inermi.

Lamina ultima ventralis longiuscula, angustiuscula, valde angustata, post rotundate truncata.

Long. $160-170 \mathrm{~mm}$.

$H a b$. This species also is spread over the whole tropical and subtropical world, and I have seen specimens from : Society Islands, Mr. A. Garrett; Pennaculum, S. India, D. C. Scudder (var.: Sc. histrionica C. L. Koch) ; Africa, without further narrative of the locality; San Francisco, Cal., T. G. Cary, Jr. (an original specimen of Dr. Wood's Sc. bispinipes).

\section{Scolopendra Indica, n. sp.}

Olivaceo-flava, ante et post obscurior, supra sæpe viridi-olivacea, capite cum antennis atque fascia media virescentibus, pedibus antennisque flavobrunneis ; minus robusta, sublævis, ante sparse leviter punctata, laminis ventralibus manifesto bisulcatis; capite fere rotundato, post arcuatim sulcato, a lamina prima dorsali partim obtecta vel laminam illam obtegens. Antennæ longiusculæ, ad basin valde incrassatæ, 17-19-articulatæ, præter articulos decem priores dense hirsutæ, articulis plurimis longiusculis.

Dentes prosternales quaterni (exteriores valde discreti), magni, truncati (exteriores acuti) ; dens coxalis major, acutus.

Pedum articulus primus tarsalis, pedibus binis posterioribus exceptis, calcare armatus.

Pedes anales breviusculi, sat incrassati, deplanati, in latere sup. interiore femoris spinulis ternis parvis, angulo apicali brevi, bi- vel trifido, in latere interiore spinulis ternis vel quinis, in series binas digestis, in latere inf. interiore spinulis binis vel quaternis, in latere inferiore spinulis septenis vel octonis, in series binas digestis, armati.

Laminæ dorsales modo tres vel quatuor posteriores marginatæ.

Pleuræ posticæ angustiusculæ, subrugosæ, dense tenuiter porosæ, in angulum breviorem vel longiorem, acutiusculum, trifidum, in latere spinula singula instructum productæ, margine postico in obliquum levissime sinuato, ad angulum exteriorem spinula parva armato.

Lamina ultima ventralis brevis, latiuscula, lateribus rotundatis, valde angustata, post latissime rotundata vel rotundate truncata.

Long. $60 \mathrm{~mm}$. 
In some respects, peculiarly with regard to the structure of the head, Sc. Indica is a connecting link between Scolopendra and the following genus Cormocephalus.

Hab. The Rev. Mr. M. Carleton has collected this Scolopendra at some places in East India; Koolloo, Himalaya; Ambala; a station 70 miles S. W. from Ambala.

\section{Gen. Cormocephalus.}

Cormocephalus Newport, Trans. Linn. Soc. Lond., xix, p. 419.

Lamina cephalica a lamina prima dorsali partim obtecta vel libera (scuta dorsalia metameri tertii manifesta).

Oculi ocellis 4 .

Antennæ breviusculæ, ad basin plus vel minus incrassatæ, ante plus vel minus attenuatæ, 17-19-articulatæ, articulis plerisque breviusculis.

Labri fimbria longa, setis longis, densis, simplicibus.

Labii processus subconici, barba e setis brevibus, densis, uncinatis facta ; palporum fimbria e setis brevibus, densis, manifesto uncinatis facta.

Palporum maxillarium unguis in latere interiore dentibus binis validis, acutiusculis armatus; fimbria digitalis longior, setis longioribus, densis, parum uncinatis, unguem medium paulum superans.

Mandibulæ ante 12-13 pectinibus juxta et pone lamellam dentatem coarctatis instructæ.

Metameri quarti sternum integrum, robustum; prosternum longe prom. inens, in dentes majores incisum; pedes prensorii articulo secundo et tertio parvis, interruptis.

Segmentum septimum absque spiraculis.

Spiracula sat profunda, magna, angusta, manifesto triangula, longitudinalia, per paria longitudine decrescentia.

Pleuræ posticæ infra porosæ, in angulum majorem vel minorem productæ.

Pedes anales breviusculi vel longiusculi, paulum incrassati, quinquearticulati, articulo primo (femore) subcarinato, spinigero, ungue sat parvo, parum arcuato unguiculis binis armato vel simplice.

I. Pedum analium unguis unguiculis binis armatus.

\section{Cormocephalus afer, n. sp.}

Flavo-olivaceus, ante obscurior, linea media dorsali pallida notatus; sat gracilis, ante robustior, sublævis, laminis ventralibus manifesto bisulcatis ; capite subovato, truncato. Antennæ breves, ad basin crassæ, attenuatæ, 17-articulatæ, præter articulos octonos priores dense brevissime hirsutæ, articulis brevibus vel breviusculis.

Dentes prosternales quaterni (exteriores discreti), majores; dens coxalis magnus, acutus. 
Pedum articulus primus tar: , pedibus binis posterioribus exceptis, calcare armatus.

Pedes anales breves vel breviusculi, sat incrassati, in latere sup. interiore femoris spinulis ternis majoribus, angulo in spinam bifidam producto, in latere interiore spinula singula, in latere inf. interiore spinulis ternis, in latere inferiore spinulis senis, in series binas obliquas digestis, armati.

Laminæ dorsales præter ultimam immarginatæ.

Pleuræ posticæ latæ vel latiusculæ, læviusculæ, dense porosæ, in angulum majorem, acutiusculum, trifidum productæ, margine postico in obliquum levissime emarginato, ad angulum exteriorem spinulis binis parvis armato.

Lamina ultima ventralis breviuscula, latiuscula, lateribus rotundatis, valde angustata, post obscure sinuata.

Long. $45 \mathrm{~mm}$.

Hab. Zanzibar, Cooke.

\section{Cormocephalus aurañtimpes.}

Scolopendra aurantipes Newport, Ann. and Mag. of Nat. Hist., xiii, p. 99. Cormocephalus aurantiipes Newport, Trans. Linn. Soc. Lond., xix, p. 420.

Kohlrausch, Arch. f. Naturg. Jahrg., 47, p. 87, tab. v, fig. 18.

Cormocephalus brevispinatus $^{\top}$. Koch, Verh. Zool. bot. Ges. z. Wien, xvii, p. 248 .

? Cormocephalus obscurus, pallipes Newport, Trans. Linn. Soc. Lond., xix, p. 421-424.

Flavo-olivaceus, fusco trilineatus, pedibus flavis; robustus, sublævis, ante sparse leviter punctatus, laminis ventralibus bisulcatis; capite subobovato, sæpe libero (lamina basali magnam partem detecta). Antennæ breviusculæ, ad basin paulum incrassatæ, attenuatæ, 17-articulatæ, præter articulos quinos vel senos priores dense brevissime hirsutæ, articulis plurimis breviusculis.

Dentes prosternales quaterni (exteriores discreti), magni obtusi; dens coxalis magnus, trilaciniatus vel simplex.

Pedum articulus primus tarsalis omnium inermis.

Pedes anales breviusculi vel breves, incrassati, in latere sup. interiore femoris spinis binis majoribus, angulo in spinam sæpe bifidam producto, in latere interiore spinula singula vel nulla, in latere inf. interiore spinulis binis, in latere inferiore carinula curvata, spinulis binis vel quaternis instructa, armati.

Laminæ dorsales præter sex vel octo priores marginatæ.

Pleuræ posticæ latiusculæ, sublæves, dense porosæ, in spinam breviorem, acutiusculam, in apice bifidam, productæ, margine postico in obliquum sinuato, inermi. 
Lamina ultima ventralis breviuscula, latiuscula vel lata, valde angustata, post rotundate truncata.

Long. $85 \mathrm{~mm}$.

Hab. Melbourne, Australia, H. Edwards. Also from America (viz: Guatemala, Ferd. von Müller; Rio de Janeiro, Thayer Exp.), I have seen two specimens, which I cannot separate from this species.

II. Pedum analium unguis inermis.

\section{Cormocephalus ambiguus.}

Cormocephalus ambiguus Newport, Trans. Linn. Soc. Lond., xix, p. 423. ? Scolopendra ambigua Brandt, Recueil, p. 63.

Gervais, Walckenaer Ins. Apt., iv, p. 263.

Flavus vel rufo-brunneus, ante et post rufescens; sat robustus, sub. læ -is, ante et post leviter punctatus, laminis ventralibus manifesto bisulcatis ; capite subovali, sæpe libero (lamina basali magnam partem detecta). Antennæ longiusculæ, ad basin crassiusculæ, attenuatæ, 17-vel 18-artic-

${ }^{-*} \Re$, præter articulos quinos priores dense brevissime hirsutæ, articulis imis longiusculis.

entes prosternales quaterni (exteriores discreti), majores ; dens coxalis ;nus, bifidus.

edum articulus primus tarsalis omnium inermis.

'edes anales longiusculi, crassiusculi, in latere sup. interiore femoris nulis binis minoribus, angulo in spinam majorem producto, in latere eriore spinula singula, in latere inf. interiore spinulis binis vel quater3, in latere inferiore carinula spinulis quinis vel senis instructa, armati. Laminæ dorsalis præter octo priores marginatæ.

Pleuræ posticæ latæ, sublæves, dense porosæ, in angulum majorem, :utiusculum, bifidum productæ, margine postico in obliquum fere truncato, suleo singulo, perparvo armato.

Lamina ultima ventralis breviuscula, lata, valde angustata, post sinuate runcata.

Long. $90 \mathrm{~mm}$.

Hab. Port Elizabeth, Cap. bon. sp., Hanson.

\section{Gen. Opisthemega.}

Opisthemega Wood, Journ. Acad. Nat. Sc. Philad., new ser., v, p. 35.

? Theatops Newport, Trans. Linn. Soc. Lond., xix, p. 410.

Lamina cephalica laminam primam dorsalem partim obtegens.

Oculi nulli vel evanidi.

Antennæ breves, ad basin incrassatæ, ante subfiliformes, 17-articulatæ, articulis brevibus vel partim longiusculis. 
Labri fimbria in medio interrupta, setis paucioribus, margine manifesto dentato.

Labii processus producti, attenuati, barba brevi e setis paucioribus, simplicibus facta; palporum fimbria e setis longis, densis, uncinatis facta.

Palporum maxillarium unguis duplex (profunde fissus) ; fimbria digitalis longa, setis longis, densis, uncinatis, unguem manifesto superans.

Mandibulæ ante 12 pectinibus juxta et pone lamellam dentatam coarctatis instructæ.

Metameri quarti sternum integrum, robustum, medium longe productum; prosternum brevius vel longius prominens, ante in dentes majores vel minores incisum; pedes prensorii articulo primo maximo, secundo et tertio parvis, interruptis, quarto solito multo minore.

Lamina basalis partim detecta.

Segmentum septimum absque spiraculis.

Spiracula sat profunda, magna, producte ovalia, fere perpendicularia, ante et post magis obliqua.

Pleuræ posticæ infra porosæ, magnam partem obtectæ, subtruncatæ.

Pedes anales perbreves, percrassi, contigui (adapti) vel fere contigni, quinquearticulati, articulo primo (femore) inermi, ungue permagno, valido, parum arcuato, inermi.

\section{Opisthemega SPINICAUdA.}

Opisthemega spinicauda Wood, Journ. Acad. Nat. Sc. Philad., new ser., v, p. 36 .

Trans. Amer. Philos. Soc., xiii, p. 170.

? Cryptops posticus Say, Journ. Acad. Nat. Sc. Philad., ii, p. 112.

? Theatops postica Newport, Trans. Linn. Soc. Lond., xix, p. 410.

Ochraceum, ante et post rufescens, minus robustum, sparse punctatum, lamina dorsali prima ante angulatim sulcata, laminis ventralibus fovea media impressis; capite subovali. Antennæ breviusculæ, tenuiusculæ, paulum attenuatæ, 17-articulatæ, ad basin sublæves, ante sparsius longius hirsutæ, articulis mediis longiusculis.

Dentes prosternales bini vel terni, evanescentes ; dens coxalis perparvus, obtusus.

Pedum tibia, articulusque primus tarsalis, pedibus binis posterioribus exceptis, calcare armata.

Pedes anales breves, crassati, fere contigui, adapti, margine sup. interiore atque inf. interiore acutis crenulatis, in latere sup. interiore femoris spinulis binis (posteriore majore), in margine inf. interiore spinulis binis vel ternis preparvus armati.

Laminæ dorsalis præter ultimam immarginatæ.

Pleuræ angustæ, subrugosæ, porosæ, truncatæ, inermes.

Lamina ultima ventralis longa, lateribus sinuatis, valde angustata, post levissime sinuata.

Long. $35 \mathrm{~mm}$. 
I have seen only one specimen, which was labeled "Opisthemega postica Wood," and is among the large number of Myriapods; which are designated as "types determined and described by Dr. H. Wood in his Myriapods of N. America "; but a little note was attached to this species: "the original catal. says spinicauda," and actually it is to be referred to Opisthemega spinicauda Wood and not to Op. postica Wood.

Hab. Acapulco, Mexico, Mr. A. Agassiz.

\section{Opisthemega crassipes, n. $\mathrm{sp}$.}

Rufo-brunneum, subtus pallidius, pedibus antennisque flavis ; minus vel sat crassum, sparse leviter punctatum, annulo ultimo pedibusque analibus densius, grossius punctatis lamina dorsali prima ante angulatim sulcata, laminis ventralibus sulco longitudinali atque transversali cruciatim exaratis ; capite subovali. Antennæ longiusculæ tenuisculæ, paulum attenuatæ, 17-vel 18-articulatæ, præter latus superius articulorum quaternorum priorum, densius brevius hirsutæ, articulis plurimis longiusculis.

Dentes prosternales bini vel terni, majores ; dens coxalis parvus acutiusculus.

Pedum tibia articulisque primus tarsalis, pedibus articis binisque posterioribus exceptis, calcare armati.

Pedes anales perbreves, percrassi, contigui, adapti, deplanati, margine sup. interiore et inf. interiore carinatis, femore inermi.

Laminæ dorsales præter ultimam immarginatæ.

Pleuræ posticæ angustæ, sublæves, porosæ, post late sinuatæ, inermes.

Lamina ultima ventralis longa, lata, lateribus parum sinuatis, valde angustata, post rotundate truncata.

Long. $36 \mathrm{~mm}$.

Hab. Jacksonville, Fla., J. A. Allen; St. Johns river, Fla.; Pennington's Gap, Lee Co., Va.; Bee Spring, Ky., F. G. Sanborn.

\section{Opisthemega insulare, n. sp.}

Flavum vel ochraceum, ante et post rufescens; sat gracile, sublæve, lamina ultima dorsali pedibusque analibus sparse leviter punctatis, lamina dorsali prima ante in formam ypsili sulcata, laminis ventralibus sulç longitudinali profundo foveam mediam secante exaratis ; capite subovali. Antennæ breviusculæ, paulum crassiusculæ, attenuatæ, 17 articulatæ, ad apicem sparsius, brevissime hirsutæ, articulis mediis longiusculis.

Dentes prosternalis bini vel terni, parvi; dens coxalis perparvus, obtusus.

Pedum tibia articulusque primus tarsalis, tibia pedum primorum pedibusque binis posterioribus exceptis, calcare armata.

PROC. AMER. PHILOS. SOC. XXIII. 122. 2A. PRINTED DECEMBER 31, 1885. 
Pedes anales breves, crassi, fere contigui, margine sup. interiore et inf. interiore carinatis manifesto serrulatis, in latere sup. interiore femoris post spinula majore armati.

Laminæ dorsales præter ultimam immarginatæ.

Pleuræ posticæ angustæ, subrugulosæ, porosæ, post late sinuatæ, inermes.

Lamina ultima ventralis longa, lateribus sinuatis, valde angustata, post rotundate truncata.

Long. $35 \mathrm{~mm}$.

Hab. Sandwich Islands, A. Garrett.

\section{Gen. Cryptops.}

Cryptops Leach, Zoöl. Miscell., iii, p. 42.

Lamina cephalica laminam primam dorsalem sæpissime partim obtegens. Oculi nulli vel evanidi.

Antennæ breviusculæ vel longiusculæ, subfiliformes, 17-articulatæ, articulis plurimis longis vel longiusculis.

Labri fimbria perbrevis, margine in lacinias setiformes, ramosas vel denticulatas inciso.

Labii processus parvi, subconici, barba brevissima, e setis paucis, simplicibus facta ; palporum fimbria brevis, e setis simplicibus vel parum uncinatis facta.

Palporum maxillarium unguis integer, inermis, gracilis, fimbria digitalis brevior, setis longis densis, valde uncinatis, unguem explens vel paulum superans.

Mandibulæ ante 7-10 pectinibus juxta et pone lamellam dentatam coarctatis instructæ.

Metameri quarti sternum integrum, subrobustum; prosternum haud prominens (obtectum), inerme; pedes prensorii articulo secundo et tertio parvis, secundo parum interrupto, tertio integro.

Lamina basalis sæpe omnino evanida.

Segmentum septimum absque spiraculis.

Spiracula profunda, parva, producte ovalia, parum obliqua vel fere prona, per paria sensim latitudine parum, longitudine vix decrescentia.

Pleuræ posticæ amplæ, liberæ, porosæ, subtruncatæ.

Pedes anales elongati, crassiusculi, quinquearticulati, aculeati, articulo tertio et quarto infra serratis, cum quinto animali mortuo spastice inflexis, ungue longo, tenuiusculo, paulum arcuato, inermi.

\section{Cryptops validus, n. sp.}

Ochraceus vel fulvus, pedibus pallidioribus ; robustus, ante sublævis vel obscure punctatus, post obscure scabrosus, laminis dorsalibus præter binas priores et posteriores quadrisulcatis, laminis ventralibus præter primam et ultimam in crucem profunde impressis, posterioribus manifestius scabrosis; 
capite subquadrato, angulis rotundatis, lateribus arcte marginatis. Antennæ longiusculæ, ad basin paulum incrassatæ, 17-articulatæ, post aculeis brevioribus sparsissime vestitæ, præter articulos quaternos priores manifesto brevissme hirsutæ, articulis plerisque breviusculis.

Dentes prosternales desunt, margine antico aculeis viginti breviusculis instructo; dens coxalis deest.

Pedes aculeis validis, breviusculis densius vestiti.

Pedes anales caduci.

Laminæ dorsales præter ultimam immarginatæ.

Pleuræ posticæ latæ, rugulosæ, parum hirsutæ, dense tenuiter porosæ, margine postico subrecto, aculeis paucis perbrevibus instructæ.

Lamina ultima ventralis longiuscula, angustiuscula, lateribus rotun. datis, multum angustata, post breviter rotundata.

Long. $45 \mathrm{~mm}$.

\section{Hab. Zanzibar, Mr. Cooke.}

\section{Cryptops Patagonicus, n. sp,}

Fulvo-brunneus, pedibus pallidioribus ; gracilis, sublævis, laminis dorsalibus præter anticam tresque posteriores sulcis binis arcuatis exaratis, laminis ventralibus præter tres posteriores in crucem manifesto impressis ; capite subcordiformi, post truncato, immarginata. Antennæ breviusculæ, ad basin vix incrassatæ, 17-articulatæ, post sparsissime longe aculeatæ, præter articulos ternos priores manifesto longius hirsutæ, articulis breviusculis.

Dentes prosternales desunt, margine antico glabro : dens coxalis deest.

Pedes aculeis longis ante sparse, post sparsissime vestiti.

Pedes anales caduci.

Laminæ dorsales præter ultimam immarginatæ.

Pleuræ posticæ angustiusculæ, semiobtectæ, aculeis paucis vestitæ, poris paucis majoribus perforatæ, margine postico subrecto, aculeis paucis tenuibus instructæ.

Lamina ultima ventralis breviuscula, lata, lateribus rotundatis, multum angustata, post latissime rotundata.

Long. $18 \mathrm{~mm}$.

Hab. Puerto Bueno, Patagonia (one single specimen).

\section{Cryptops sulcatus, n. sp.}

Fulvo-brunneus, pedibus antennisque pallidioribus; pergracilis, sublæris, laminis dorsalibus præter anticam et ultimam sulcis senis (mediis cbsoletioribus, exterioribus arcuatis) in corpore medio profundioribus exaratis, laminis ventralibus præter anticam duasque posteriores in crucem (sulco longitudinali lato, profundo, manifestiore) impressis, capite subovali, post truncato, immarginato. Antennæ breves, ad basin paulum incrassatæ, 17(16)-articulatæ, post densius longius aculeatæ, sparse hiısutæ, ante sparsissime, brevius aculeatæ, densius hirsutæ, articulis brevibus. 
Dentes prosternales desunt, margine antico glabro ; dens coxalis evanidus.

Pedes aculeis longis ante sparse, post sparsissime vestiti.

Pedes anales caduci.

Laminæ dorsales præter ultimam immarginatæ,

Pleuræ posticæ latiusculæ, subliberæ, subglabræ, poris paucioribus subseriatis majoribus perforatæ, margine postico subrecto, aculeis paucis tenuibus instructæ.

Lamina ultima ventralis, breviuscula lata, lateribus subrectis, valde convergentibus, post latissime sinuata.

Long. $15 \mathrm{~mm}$.

Hab. Bee Spring, Ky., F. G. Sanborn.

2. Fam. GEOPHILINI.

Segmenta pedifera numerosa (31-173 paria), inter se æqualia.

Pedes breves, tarsis integris.

Antennæ 14-articulatæ.

Oculi nulli.

(Pedes prensorii articulo secundo et tertio semper in latere exteriore evanidis vel interruptis. )

Lamina basalis semper manifesta.

Spiraculorum paria numerosa, segmentis numero paulo deteriora.

\section{Gen. Mecistocephalus.}

Mecistocephalus (Newport) Meinert, Myriap. Mus. Haun. i. Geophil., p. 92.

Corpus subdepressum, post plus vel minus angustatum.

Lamina cephalica trophos pro parte minore obtegens, elongata ; lamina frontalis discreta; lamina basalis angustata, lateribus ante paulum convergentibus; lamina præbasalis obtecta.

Antennæ sat longæ, vel longæ, filiformes.

Labrum liberum, tripartitum, parte media angustata, margine antico glabro.

Labii sternum bipartitum; processus producti ; palpi simplices, producti, integri.

Palporum maxillarium unguis major vel minor.

Mandibulæ ante lamellis pluribus dentatis instructæ.

Metameri quarti sternum subquadratum, ante dentibus duobus parvis armatum; prosternum haud prominens, obtectum ; pedes prensorii articulo ultimo (ungue) ad basin dente armato.

Scutella spiraculifera parva, præscutello pluries minora, postscutella magnitudinis fere scutelli, discreto; scutella atque præscutella media et interna evanida.

Laminæ dorsales manifesto bisulcatæ.

Pori ventrales inconspicui.

Pori pleurales numerosi, in yentre et dorso siti. 
Pedes anales sexarticulati, inermes ; feminæ tenues vel tenuissimi, maris modice incrassati, articulo primo parvo.

- Lamina ultima ventralis triangula, præscutis discretis. Palpi genitales maris sat breves, biarticulati.

\section{Mecistocephalus punctifrons.}

Mecistocephalus punctifrons Newport, Proc. Zool. Soc. 1842, p. 179, Trans. Linn. Soc. Lond., xix, p. 429, tab. 33, fig. 17.

Meinert, Myriap. Mus. Haun. i. Geophil., p. 97.

Mecistocephalus heteropus Humbert, Essai Myriap. Ceylan, p. 19, tab. ii, fig. $4,4 a-4 d$.

? Mecistocephalus Guildingii Newport, Trans. Linn. Soc. Lond., xix, p.429, tab. 33, figs. 18-19.

Meinert, Myriap. Mus. Haun. i. Geophil., p. 96.

Minus robustus, post manifesto attenuatus; ochraceus vel fulvis, capite cum trophis laminaque prima dorsali dilute castaneis, antennis pedibusque flavis; sparsissime_breviter pilosus, pedibus densius pilosis.

Pedes prensorii breviter vel brevissime, densius pilosi, flexi articulum primum antennarum explentes; sternum multo latius quam longius (5:4), coxa paulo longius, margine antico in medio alte sinuato, dentibus angularibus manifestis, acutis; coxa dentibus binis magnis armata; unguis dente majore, setoso armatus.

Lamina cephalica vix duplo longior quam latior (fere $9: 5$ ), sparsissime foveolata, foveis sex sulcos duos posticos, breves explentibus, marginem anticum laminæ basalis obtegens; lamina basalis multo latior quam longior $(7: 5)$.

Antennæ breviusculæ vel longiusculæ, articulis brevibus, primis subnodiformibus, paulum compressis.

Laminæ dorsales sublæves, præter ter vel quatuor priores atque tot posteriores manifesto bisulcatæ (5-20 obsolete foveolatæ), præscutis anterioribus obtectis vel brevissimis, mediis atque posterioribus longis.

Spiracula anteriora magna (antica maxima, subovalia, perpendicularia) subrotunda; media et posteriora minuta, rotunda.

Laminæ ventrales anteriores præter primam impressione ypsiliformi notatæ, posteriores in medio manifesto sulcatæ, scabrosæ.

Pedes paris primi perminuti ; ceteri sat longi, anteriores manifesto breviores atque crassiores.

Pleuræ posticæ sat vel parum amplæ, densius pilosæ, poris minus numerosis, minutis infra instructæ, margine interiore late, breviter hirsuto;

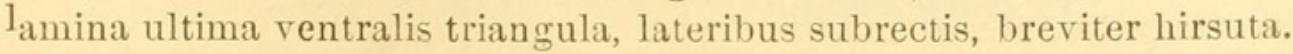

Pedes anales pedibus paris anterioris valde longiores, paulo tenuiores, 
breviter hirsuti, articulis prioribus sparsius (ㅇ) vel densius $\left(\sigma^{\top}\right)$ breviter hirsutis.

Pedes feminæ pp. 49, maris 49 . Long. feminæ $52 \mathrm{~mm}$., maris $50 \mathrm{~mm}$. Lat. feminæ $1.7 \mathrm{~mm}$, maris $1.8 \mathrm{~mm}$.

$H a b$. The Rev. Mr. Carleton has presented eight specimens of this species, all from East India; Koolloo, near Himalaya; Ambala; a station 70 miles S. W. from Ambala.

\section{Mecistocephalus heros, n. sp.}

Robustus, post valde attenuatus; ochraceus, in dorso atque lateribus dense nigro-marmoratus, capite cum trophis laminaque prima dorsali castaneis, antennis pedibusque flavis; ante subglaber, post in ventre atque lateribus dense et breviter hirsutus, pedibus breviter pilosis.

Pedes prensorii subglabri, flexi articulum primum antennarum fere explentes; sternum vix sesqui latius quam longius (10:7), coxa multo longius (fere 5:4), margine antico alte sinuato, simplice; coxa dente obtuso armata, supra glabra; unguis dente evanido armatus.

Lamina cephalica vix duplo longior quam latior $(9: 5)$, sparsissime foveolata, foveis decim vel duodecim in duas series digestis, sulcum posticum, medium, brevem explentibus, marginem anticum laminæ basalis obtegens; lamina basalis bis vel ter latior quam longior (fere $5: 2$ ).

Antennæ perlongæ, articulis ternis prioribus subclaviformibus, ceteris teretibus, longius vel perlongis.

Laminæ dorsales sublæves, præter quatuor vel quinque priores atque tot posteriores manifesto bisulcatæ, præscutis anterioribus obtectis vel brevissimis, mediis atque posterioribus longis.

Spiracula anteriora magna (antica maxima), subovalia, perpendicularia ; media et posteriora minuta, rotunda.

Laminæ ventrales anteriores et mediæ, præter duas anticas, impressione ypsiliformi notatæ; posteriores in medio sulcatæ, sulco post sensim evanescente.

Pedes paris primi brevissimi ; ceteri sat longi, anteriores paulo breviores, manifesto crassiores.

Pleuræ posticæ sat amplæ, dense pilosæ, poris majoribus atque minoribus, numerosis, subseriatis infra et supra instructæ; latere interiore breviter hirsuto ; lamina ultima ventralis trapezoidea, lateribus subrectis, post breviter hirsuta.

Pedes anales pedibus paris anteriores valde longiores, manifesto tenuiores, pilosi.

Pedes maris pp. 49. Long. maris $83 \mathrm{~mm}$. Lat. maris $4.5 \mathrm{~mm}$.

Hab. St. Mauritius Island, N. Pike.

3. Mecistocephalus breviceps, n. sp.

Sat robustus, post modice attenuatus; ochraceus, capite cum trophis 
dilute castaneo, antennis fulvis, pedibus flavis; subglaber, pedibus setis sparse vestitis.

Pedes prensorii subglabri, flexi articulum primum antennarum non explentes; sternum sesqui latius quam longius, coxa vix sesqui longius $(10: 7)$, margine antico in medio alte sinuato, dentibus angularibus manifestis ; coxa dente obtuso armata ; unguis dente minuto armatus.

Lamina cephalica sesqui longior quam latior, foveolis pauois subseriatis impressa, marginem anticum laminæ basalis obtegens; lamina basalis (magnam partem obtecta) quater latior quam longior.

Antennæ breviusculæ, articulis mediis longioribus.

Laminæ dorsales sublæves, præter primam atque posteriores leviter bisulcatæ, præscutis anterioribus brevissimis, post sensim longioribus, posterioribus longis.

Spiracula anteriora magna (antica maxima), subovalia, perpendicularia ; media et posteriora minuta, rotunda.

Laminæ ventrales anteriores præter primam in medio sulco profundo vel post magis obsoleto, marginem attingente, exaratæ, laminæ posteriores sublæves.

Pedes paris primi breves; ceteri sat longi, anteriores paulo breviores atque crassiores.

Pleuræ posticæ sat amplæ, hirsutæ, poris majoribus atque minoribus, numerosis, subseriatis, infra et supra instructæ; margine interiore late hirsuto, lamina ultima ventralis triangula, lateribus subrectis, post breviter hirsuta,

Pedes anales pedibus paris anterioris manifesto longiores, breviterdensius pilosi.

Pedes maris, pp. 45. Long. maris $65 \mathrm{~mm}$. Lat. maris $2.5 \mathrm{~mm}$.

\section{Hab. Nantucket, Mass.}

\section{Gen. Geophilus.}

Geophilus (Leach) Meinert, Myriap. Mus. Haun. i. Geophil., p. 58.

Corpus depressum vel subdepressum, ante vix, post modice angustatum.

Lamina cephalica trophos non obtegens; lamina frontalis sæpissime discreta, lamina basalis minus lata vel angusta, lateribus ante convergentibus ; lamina præbasalis partim vel omnino obtecta.

Antennæ plus vel minus longæ, filiformes vel subfiliformes.

Labrum liberum, tripartitum, in dentes vel lacinias incisum.

Labii sternum integrum ; processus sat parvi ; palpi biarticulati, in latere exteriore processibus binis longis instructi.

Palporum maxillarium unguis major vel minor.

Mandibulæ ante lamina singula pectinata instructæ.

Metameri quarti sternum integrum, lineis duabus chitineis abbreviatis vel integris fultum, margine antico inermi vel dentibus duobus parvis in- 
structo ; prosternum haud prominens, obtectum ; pedes prensorii articulo ultimo (ungue) dente basali sæpissime armato.

Scutella spiraculifera parva vel minima, præscutello pluries minora, postscutello majore discreto ; scutella atque præscutella media et interna evanida.

Laminæ dorsales manifesto bisulcatæ; præscuta plurima magna vel longa.

Pori ventrales plus vel minus manifesti.

Pori pleurales multi vel pauciores aut nulli, in ventre solummedo vel etiam in dorso siti.

Pori anales duo aut nulli.

Pedes anales sexarticulati, ungue armati aut inermes ; feminæ graciles, maris graciles vel minus incrassati, articulo primo parvo.

Lamina ultima ventralis angusta aut lata, præscutis a lamina discretis, inter se coalitis aut non coalitis. Palpi genitales maris biarticulati.

A. Lamina frontalis discreta.

(Pori anales nulli).

\section{Geophilus cephalicus.}

Geoplitus cephalicus Wood, Journ. Acad. Nat. Sc. Philad., new ser., v, p. 44.

Trans. Amer. Philos. Soc., xiii, p. 178.

Geoplilus lavis Wood, Journ. Acad. Nat. Sc. Philad., new ser., v, p. 44.

Trans. Amer. Philos. Soc., xiii, p. 180.

Sat robustus ante vix, post paulum angustatus; testaceus, capite cum trophis antennisque dilute brunneo, striga lata, duplice, interrupta, obscura in dorso medio notatus; sublævis.

Pedes prensorii læves, flexi marginem frontalem spatio majore vel magno superantes; sternum simplex oblingulatum, multo latius quam longius (fere $4: 3$ ), coxa duplo longius, margine antico in angulum, in medio sinuatum, producto, inermis ; coxa inermis ; unguis incurvus, dente minuto vel minimo, nodiformi armatus.

Lamina cephalica fere æque longa ac lata, lævis, subovalis, angulos priores laminæ basalis obtegens; lamina basalis quater latior quam longior, ante alte emarginata, lamina præbasali parvam partem libera.

Antennæ breviusculæ vel longiusculæ, articulis prioribus præter primum longiusculis.

Laminæ dorsales foveis binis longitudinalibus impressæ, manifesto bisulcatæ, præscutis anterioribus brevibus, mediis et posterioribus longis.

Spiracula rotunda, anteriora (præsertim antica) magna; media et posteriora minuta.

Laminæ ventrales in medio sulcatæ, in angulis fovea porosa vel rotunda (in angulis prioribus) vel transversali (in angulis posterioribus) obsolete exaratæ. 
Pedes paris primi ceteris manifesto breviores atque tenuiores, anteriores quam posteriores paulo breviores atque crassiores.

Pleuræ posticæ parum inflatæ, glabræ, foveis binis obliquis, poriferis, semiobtectis instructæ; lamina ultima ventralis perlata, lateribus valde convergentibus; rotundatis.

Pedes anales pedibus paris anterioris paulo longiores, paulo (feminæ) vel valde (maris) crassiores, subglabri (feminæ) vel hirsuti (maris), ungue valido armati.

Pedes feminæ pp. 51-53; maris 49. Long. feminæ $47 \mathrm{~mm}$. ; maris 37 mm. Lat. feminæ $2 \mathrm{~mm}$.'

Hab. Fred. Co., Md., P. R. Uhler (the type of Dr. Wood); Michigan, E. P. Austin; Charl. Co., Md., Bryant. One specimen was labeled Zanzibar (an recte?).

\section{Geophilus mordax, n. sp.}

Minus robustus, post manifesto angustatus; fulvus, pedibus flavis; subglaber, pedibus pilis brevioribus sparsissime vestitis.

Pedes prensorii subglabri, flexi marginem frontalem vix attingentes; sternum lineis duabus chitineis, integris fultum, sesqui latius quam longius, coxa fere duplo longius ( $20: 11)$, margine antico longe producto, in medio alte sinuatus, inermis; coxa inermis; unguis valde curvatus, dente minimo, obtuso armatus.

Lamina cephalica fere æque longa ac lata, subglabra, subovalis, angulos priores laminæ basalis obtegens; lamina basalis ter latior quam longior, lamina præbasali partem minimam libera.

Antennæ longiusculæ vel longæ, articulis prioribus præter primum longiusculis, articulo ultimo articulos duos antecedentes conjunctos longitudine procul æquante.

Laminæ dorsales sublæves, manifesto bisulcatæ.

Spiracula anteriora ovalia vel subovalia, perpendicularia, magna vel permagna, per paria sensim magnitudine decrescentia ; media et posteriora rotunda, minuta.

Lamina ventrales anteriores sulco medio, profundo, abbreviato areaque postica transversali, porosa, mediæ et posteriores sulco minus profundo, integro exaratæ.

Pedes paris primi ceteris paulo breviores atque tenuiores, anteriores quam posteriores paulo breviores atque crassiores.

Pleuræ posticæ vix inflatæ, subglabræ, poris denis vel duodenis magnis, subseriatis instructæ; lamina ultima ventralis minus lata, lateribus subrectis, manifesto convergentibus.

Pedes anales caduci.

Pedes feminæ pp. 51. Long. $25 \mathrm{~mm}$. Lat. $1.2 \mathrm{~mm}$.

Hab. The specimen had no more distinct indication than $\mathrm{U}$. S. A.

PRoc. Amer. Philos. Soc. XXIII. 122. 2B. PRinted DeCEMBer 31, 1885. 
B. Lamina frontalis coalita.

a. Pori anales nulli.

\section{Geophilus marginalis, n. sp.}

Sat robustus, post manifesto angustatus; flavus, capite cum trophis laminaque prima dorsali dilute brunneo, striga lata, duplice, interrupta, obscura in dorso medio notatus, lateribus maculis obscuris, densis irroratis ; pilis longioribus densius vestitus.

Pedes prensorii pilis brevibus densius vestiti, flexi articulum primum antennarum spatio majore superantes ; sternum simplex, multo latius quam longius (fere $7: 6$ ), coxa vix sesqui longius, margine antico in medio profunde sinuato, dentibus duobus brevibus armato; coxa dente majore, obtuso armata ; unguis parum curvatus, dente magno, acuto armatus.

Lamina cephalica vix sesqui longior quam latior (fere $10: 7$ ), sat grosse, densius punctata, sulcis duobus longioribus obsolete impressa, lateribus subrectis, post paulum convergentibus, marginem anticum laminæ præbasalis obtegens ; lamina basalis ter vel quater latior quam longior (fere $25: 7$ ).

Antennæ longæ vel perlongæ, articulis prioribus præter primum longis vel perlongis, articulo ultimo duobus antecedentibus conjunctis paulo breviore.

Laminæ dorsales sat grosse punctatæ, foveis binis longis manifesto exaratæ, obscurius bisulcatæ, præscutis anterioribus brevissimis, mediis et posterioribus longiuscúlis.

Spiracula bina priora ovalia, perpendicularia, magna vel permagna, cetera rotunda, minuta vel perminuta.

Laminæ ventrales profunde sulcatæ, anteriores areis vel foveis quaternis porosis exaratæ.

Pedes paris primi ceteris multo breviores atque tenuiores, anteriores quam posteriores paulo breviores, multo crassiores.

Pleuræ posticæ parum inflatæ, sparse pilosæ, poris numerosis, parvis, seriatis in ventre et dorso instructæ; lamina ultima ventralis angusta, lateribus subrectis, manifesto vel valde angustatis.

Pedes anales (maris) pedibus paris anterioris paulo longiores, valde crassiores, ungue evanido.

Pedes maris pp. 61 . Long. $46 \mathrm{~mm}$. Lat. $1.6 \mathrm{~mm}$.

Hab. Key West, Fla. (one single specimen).

\section{Geophilus urbicus, n. sp.}

Minus robustus, post multum attenuatus ; fulvus ; pilis brevibus sparsissime vestitus, pedibus pilis longioribus sparse vestitis.

Pedes prensorii subglabri, flexi marginem frontalem procul attingentes ; sternum simplex, sesqui latius quam longius, coxa plus sesqui longiores (5:3), margine antico in madio late sinuato, dentibus duobus obtusis, 
evanidis armato ; coxa dente parvo, acuto armata ; unguis valde curvatus, dente minuto, obtuso armatus.

Lamina cephalica fere æque longa ac lata, subglabra, sulcis duobus transversalibus ante marginem posticum impressa, lateribus rotundatis, manifesto convergentibus, angulos priores laminæ basalis obtegens. margine postico late sinuato; lamina basalis vix quater latior quam longior, lamina præbasali partim libera.

Antennæ breviusculæ, dense hirsutæ, articulis prioribus præter primum longiusculis, articulo ultimo articulos duos antecedentes conjunctos longitudine manifesto superante.

Laminæ dorsales foveis binis obsoletis exaratæ, obsolete bisulcatæ, præscutis anterioribus et posterioribus brevibus, mediis longis vel perlongis.

Spiracula rotunda, anteriora parva, per paria sensim magnitudine decrescentia, media et posteriora perminuta.

Laminæ ventrales anteriores sulco medio profundo notatæ, mediæ et posteriores sulcis ternis obsoletioribus, post sensim evanescentibus exaratæ.

Pedes paris primi ceteris subæquales, anteriores posterioribus subæquales.

Pleuræ posticæ paulum inflatæ, pilis longioribus sparse vestitæ, poris vicenis magnis vel permagnis (posticis) instructæ ; lamina ultima ventralis angusta, lateribus subrectis, parum convergentibus.

Pedes anales pedibus paris anterioris paulo breviores, multo crassiores, ungue magno armati.

Pedes feminæ pp. 41. Long. $22 \mathrm{~mm}$. Lat. $1.1 \mathrm{~mm}$.

\section{Hab. Cambridge, Mass., E. Schwarz (one single specimen).}

\section{Geophilus Georgianus, n. sp.}

Sat gracilis, post manifesto attenuatus; ochraceus vel flavus, capite cum trophis dilute brunneo, pedibus testaceis ; subglaber, pedibus pilis longioribus, sparsis vestitis.

Pedes prensorii subglabri, flexi marginem frontalem spatio magno superantes ; sternum simplex, multo latius quam longius $(7: 6)$, coxa vix duplo longius (20:11), margine antico in medio late sinuato, inermi; coxa dente evanido armata ; unguis curvatus, dente minuto armatus.

Lamina cephalica multo longior quam latior $(9: 7)$, pilis paucis, brevibus vestita, sulcis duobus longis ante marginem posticum obsolete impressa, subovalis, marginem anticum laminæ basalis obtegens; laminæ basalis pars libera plus duplo latior quam longior $(7: 3)$.

Antennæ longæ, in latere exteriore dense pilosæ, articulis prioribus præter primum longis, articulo penultimo articulis duobus antecedentibus conjunctis manifesto breviore.

Laminæ dorsales foveolis binis longitudinalibus obsolete notatæ, manifesto bisulcatæ, præscutis longiusculis vel longis, posterioribus paulo longioribus. 
Spiracula rotunda, anteriora mıgna, per paria sensim magnitudine de. crescentia, media et posteriora minuta.

Laminæ ventrales anteriores in medio profunde sulcatæ, pone sulcum area transversali, angusta, porosa notatæ.

Pedes paris primi ceteris multo breviores atque tenuiores, anteriores posterioribus paulo breviores atque crassiores.

Pleuræ posticæ parum inflatæ, poris singulis, validis, obtectis.

Pedes anales pedibus paris anterioris valde longiores, manifesto crassiores, pilis brevibus, sparsis vestiti, ungue evanido armati.

Pedes feminæ pp. 61. Long. $34 \mathrm{~mm}$. Lat. $0.9 \mathrm{~mm}$.

Hab. Georgia (one single specimen).

\section{b. Pori anales parvi.}

\section{Geophilus occidentalis, n. sp.}

Sat gracilis, post manifesto angustatus; ochraceus, capite cum trophis dilute brunneo, antennis flavis ; subglaber, pedibus longe, sparse pilosis.

Pedes prensorii subglabri, flexi articulum primum antennarum fere explentes; sternum simplex, æque longum ac latum, coxa sesqui longius, margine antico in medio alte sinuato, angulis integris ; coxa dente obtuso armata ; unguis dente nodiformi, minore armatus.

Lamina cephalica vix sesqui longior quam latior, post paulum angustata, foveolis minutis, sparsis, subseriatis sulcisque duobus brevibus, obsoletis notata ; lamina basalis libera, fere ter latior quam longior.

Antennæ longæ, articulis plurimis longis.

Laminæ dorsales sublæves, manifesto bisulcatæ, præscutis anterioribus perbrevibus, mediis longis, posterioribus longiusculis.

Spiracula præter antica parva, rotunda ; antica subovalia.

Laminæ ventrales anteriores profunde sulcatæ, mediæ atque posteriores obsolete impressæ.

Pedes paris primi ceteris manifesto breviores, anteriores quam posteriores paulo crassiores.

Pleuræ posticæ vix inflatæ, poris novenis vel denis liberis, majoribus vel minoribus atque singulo magno, distante instructæ ; lamina ultima ventralis angustiuscula, longa, post manifesto angustata.

Pedes anales subglabri, crassiusculi, ungue evanido.

Pedes maris pp. 73 . Long. $39 \mathrm{~mm}$. Lat. $1 \mathrm{~mm}$.

Hab. San Francisco, Cal., T. G. Cary, Jr. (one single specimen.)

c. Pori anales magni.

\section{Geophilus Huronicus, n. sp.}

Sat vel minus robustus, post manifesto angustatus; flavus, capite cum trophis dilute brunneo, pedibus testaceis vel flavis; subglaber, pedibus pilis longioribus sparse vestitis. 
Pedes prensorii subglabri, flexi marginem frontalem spatio majore vel minore superantes; sternum simplex, multo latius quam longius (fere 6 : 5 ), coxa plus sesqui longius (5:3), margine antico altius sinuato, inermi ; coxa dente evanido armata; unguis dente minuto armatus.

Lamina cephalica paulo longior quam latior (fere $10: 9$ ), sparse minus grosse punctata, sulcis duobus sat longis obsolete exarata, subovalis, partem majorem laminæ basalis obtegens; lamina basilis ter latior quam longior.

Antennæ longæ vel perlongæ, articulis præter primum et ultimos longis, articulo ultimo articulis duobus antecedentibus conjunctis manifesto breviore.

Laminæ dorsales fovea media, obsoleta exaratæ, manifesto bisulcatæ, præscutis anterioribus brevissimis vel brevibus, mediis et posterioribus longiusculis vel brevibus.

Spiracula rotunda, anteriora magna per paria sensim magnitudine decrescentia ; media et posteriora minuta.

Laminæ ventrales manifesto sulcatæ, anteriores et mediæ pone medium area magna, transversali, porosa vel integra (in anterioribus) vel bipartita (in mediis) notatæ.

Pedes paris primi ceteris multo breviores atque tenuiores, anteriores posterioribus vix breviores, paulo crassiores.

Pleuræ posticæ vix inflatæ, pilis brevibus sparse vestitæ, poris senis vel octonis majusculis, maximam partem obtectis instructæ; lamina ultima ventralis lata, lateribus subrectis, paulum convergentibus.

Pedes anales pedibus paris anterioris valde longiores, paulo (feminæ) vel multo (maris) crassiores, ungue majore (feminæ) vel minore (maris) armati.

Pedes feminæ pp. 55-57; maris 53-55. Long. feminæ $33 \mathrm{~mm}$. ; maris $30 \mathrm{~mm}$. Lat. feminæ $1 \mathrm{~mm}$.; maris $1.2 \mathrm{~mm}$.

Hab. I have seen four specimens of this species; the two were labeled Massachusetts, and the two others "N. Engl."

\section{Gen. Scolioplanes.}

Scolioplanes (B. \& M.) Meinert, Myriap. Mus. Haun. i. Geophil., p. 48.

Corpus subdepressum, ante et post attenuatum.

Lamina cephalica trophos non omnino obtegens; lamina frontalis dis. creta aut coalita ; lamina basalis transversalis ; lamina præbasalis in duas lamellas partita, obtecta aut detecta.

Antennæ plus vel minus longæ, filiformes, hirsutæ.

Labrum liberum, tripartitum, partis mediæ margine antico in dentes multos inciso.

Labii sternum integrum; processus sat magni; palpi integri vel bi. partiti, simplices.

Palporum maxillarium unguis parvus.

Mandibulæ ante lamina singula pectinata instructæ. 
Metameri quarti sternum integrum, simplex; prosternum haud prominens, obtectum; pedes prensorii articulo ultimo (ungue) dente basali valido armato.

Scutella spiraculifera sat magna, præscutello duplo vel triplo minora, postscutello minore discreto; scutella et præscutella media et interna evanida.

Laminæ dorsales læves; præscuta longiora vel breviora.

Pori ventrales parvi vel minimi, in aream transversalem, posticam dispositi.

Pori pleurales plures vel pauciores.

Pori anales duo, parvi.

Pedes anales sexarticulati; feminæ gracilis, attenuati, maris percrassi vel crassi, hirsuti, articulo primo parvo.

Lamina ultima ventralis longa, lateribus postconvergentibus, præscutis discretis. Palpi genitales maris integri.

I. Lamina frontalis discreta.

\section{Scolioplanes Bothriopus.}

? Strigamia bothriopus Wood, Journ. Acad. Nat. Sc. Philad., new ser., v, p. 46.

Trans. Amer. Philos. Soc., xiii, p. 182.

? Strigamia flava Sayer, Proc. Acad. Nat. Sc. Philad., viii, p. 109.

Wood, Trans. Amer. Philos. Soc., xiii, p. 183.

Minus robustus, ante et post multum attenuatus ; 'fulvus, capite cum trophis dilute brunneo; pilis brevibus sparse vestitus, pedibus pilis breviusculis densius vestitis.

Pedes prensorii pilis breviusculis sparse vestiti, flexi marginem frontalem spatio magno non attingentes ; sternum stricte cordiforme vix duplo latius quam longius (fere $9: 5$ ), coxa bis vel ter longius (5:2), margine antico in medio alte sinuato, inermi ; coxa inermis ; unguis parum curvatus, dente valido, acuto armatus.

Lamina cephalica paulo latior quam longior $(10: 9)$, pilis longioribus sparse vestita, læviuscula, lateribus rotundatis, manifesto divergentibus, margine postico a lamina basali obtecta ; lamina basalis bis vel ter latior quam longior (fere $5: 2$ ).

Antennæ longiusculæ, articulis prioribus præter primum longiusculis, articulo ultimo articulos duos antecedentes conjunctos longitudine subæquante.

Laminæ dorsales læviusculæ, præscutis longiusculis vel longis.

Spiracula rotunda, magna vel majuscula, anteriora posterioribus paulo majora.

Laminæ ventrales fovea media, obsoleta areaque magna, duplice, porosa ante marginem posticum notatæ. 
Pedes paris primi ceteris manifesto breviores, anteriores et posteriores subæquaies.

Pleuræ posticæ parum inflatæ, pilis longioribus sparse vestitæ, poris tredenis vel sedenis (præter unum distantem in series rotundatas digestis) parvis et majusculis instructæ ; lamina ultima ventralis angusta, lateribus curvatis, convergentibus.

Pedes anales pedibus paris anterioris paulo breviores, vix (feminæ) vel valde (maris) crassiores, ungue parvo armati.

Pedes feminæ pp. 51 ; maris $47-51$. Long. feminæ $24 \mathrm{~mm}$. ; maris 35 $\mathrm{mm}$. Lat. maris $1.3 \mathrm{~mm}$.

The specimen of the Museum of Comp. Znöl. was labeled "Strigamia fulva Say," determined by Dr. Wood.

Hab. Massachusetts.

\section{Scolioplanes Chionophilus.}

? Strigamia chionophila Wood, Journ. Acad. Nat. Sc. Philad., new ser., v, p. 50 .

Trans. Amer. Philos. Soc., xiii, p. 189.

Minus robustus, ante et post multum attenuatus; fulvus, capite cum trophis dilute brunneo; pilis brevibus sparse vestitus, pedibus pilis longioribus sparse vestitis.

Pedes prensorii subglabri, flexi marginem frontalem non attingentes; sternum subcordiforme, paulo latius quam longius $(10: 9)$, coxa bis vel ter longius $(5: 2)$, margine antico in medio late sinuato, inermi ; coxa in. ermis ; unguis valde curvatus, dente valido, acuitiusculo armatus.

Lamina cephalica multo latior quam longior (5:4), subglabra, læviuscula, lateribus paulum rotundatis, manifesto divergentibus, margine postico subrecto, laminam basalem plus vel minus obtegente; lamina basalis plus ter latior quam longior (fere $10: 3$ ).

Antennæ breviusculæ, articulis præter primum el ultimum breviusculis, articulo ultimo articulos duos antecedentes conjunctos longitudine subæquante.

Laminæ dorsales læviusculæ, præscutis anterioribus brevibus vel brevissimis, mediis et posterioribus longis vel perlongis.

Spiracula rotunda, anteriora parva, media et posteriora minuta.

Laminæ ventrales foveis ternis in seriem mediam transversalem digestis plus vel minus manifesto exaratæ.

Pedes parium trium priorum per paria sensim longitudine manifesto crescentes, ceterorum anteriores posterioribus subæquales.

Pleuræ posticæ coxiformes, subglabræ, poris novenis vel tredenis in obliquum subseriatis, magnis et permagnis instructæ; lamina ultima ven tralis triangula.

Pedes anales pedibus paris anterioris subæquales, ungue minore (feminæ) vel paulo crassiores, ungue longo (maris). 
Pedes feminæ pp. 39 : maris 41 . Long. feminæ $22 \mathrm{~mm}$. ; maris $25 \mathrm{~mm}$. Lat. maris $1.3 \mathrm{~mm}$.

Hab. Cambridge, Mass., Mr. E. Schwarz.

\section{Scolioplanes robustus, n. sp.}

Sat robustus, ante et post vix angustatus ; fulvus, capite cum trophis laminaque basali et prima dorsali dilute brunneo; subglaber, pedibus pilis brevibus sparsissime vestitis.

Pedes prensorii subglabri, flexi marginem frontalem spatio magno non attingentes; sternum subcordiforme, plus sesqui latius quam longius ( $5: 3)$, coxa plus duplo longius $(9: 4)$, margine antico in medio alte sinuato, inermi; coxa inermis; unguis parum curvatus, dente valido, - acuto armatus.

Lamina cephalica paulo latior quam longior (10:9), subglabra, læviuscula, lateribus rotundatis, manifesto divergentibus, margine postico a lamina basali vix obtecto ; lamina basalis quam lamina cephalica duplo brevior, bis vel ter latior quam longior $(5: 2)$.

Antennæ longæ, articulis prioribus præter primum longis, articulo ultimo articulis duobus antecedentibus conjunctis manifesto breviore.

Laminæ dorsales læviusculæ, præscutis breviusculis.

Spiracula rotunda, sat magna.

Laminæ ventrales fovea media oblonga, post sensim obsoletiore, areisque duabus duplicibus, porosis ante marginem posticum exaratæ.

Pedes paris primi ceteris manifesto breviores, anteriores quam posteriores paulo breviores et crassiores.

Pleuræ posticæ modice inflatæ, glabræ, poris vicenis magnis et permagnis, subseriatis instructæ; lamina ultima ventralis angusta, triangula, parva.

Pedes anales pedibus paris anterioris paulo breviores atque tenuiores, ungue majusculo armati.

Pedes feminæ pp. 53. Long. $40 \mathrm{~mm}$. Lat. $2.1 \mathrm{~mm}$.

Hab. This species had no more distinct locality than N. A.?

\section{Scolioplanes exul, n. sp.}

Robustus, ante valde post parum angustatus, fulvus; pedibus flavis ; pilis brevissimis sparse vestitus, pedibus pilis brevioribus sparse vestitis.

Pedes prensorii pilis brevissimis et brevibus densius vestiti ; flexi marginem frontalem fere attingentes ; sternum subcordiforme, plus sesqui latius quam longius (5:3), margine antico in medio alte sinuato, inermi ; coxa inermis ; unguis curvatus, dente valido, acutiusculo armatus.

Lamina cephalica' æque longa ac lata, pilis brevibus sparse vestita, læviuscula, subovalis, margine postico subrecto, laminam præbasalem fere totam obtegente; lamina basalis quam lamina cephalica vix ter brevior, plus ter latior quam longior. 
Antennæ longæ, subfiliformes, articulis prioribus præter primum longis, articulo ultimo articulis duobus antecedentibus conjunctis manifesto - breviore.

Laminæ dorsales læviusculæ, præscutis breviusculis.

Spiracula rotunda magna vel permagna, anteriora per paria sensim mag. nitudine decrescentia.

Laminæ ventrales anteriores in medio profunde sulcatæ, foveis binis obsoletioribus, lateralibus areisque binis magnis, porosis ante marginem posticum exaratæ, mediæ et posteriores in medio obsoletius (ante) vel manifestius (post) sulcatæ, ante marginem posticum area permagna, transversali, porosa notatæ.

Pedes paris primi ceteris manifesto breviores et tenuiores, anteriores et posteriores subæquales.

Pleuræ posticæ coxiformes, sat inflatæ, pilis brevioribus densius vestitæ, poris denis magnis, partim obtectis instructæ; lamina ultima ventralis brevis, transversalis, lateribus subvectis, valde convergentibus.

Pedes anales pedibus paris anterioris manifesto longiores, valde in crassati, compressiusculi, articulo ultimo quam penultimo multoties minore, conico, ungue evanido armato.

Pedes maris pp. 65. Long. $45 \mathrm{~mm}$. Lat. $2.2 \mathrm{~mm}$.

Hab. This new species was labeled "No Loc."

II. Lamina frontalis coalita.

\section{Scolioplanes Parviceps.}

\section{? Strigamia parviceps Wood, Trans. Amer. Philos. Soc., xiii, p. 187.}

Minus robustus, ante multum post manifesto angustatus; flavus, concolor, vel ante et post fulvus; glaber.

Pedes prensorii glabri, flexi marginem frontalem procul attingentes; sternum vix duplo latius quam longius (fere $9: 5$ ), coxa duplo longius, margine antico in medio rectangulatim inciso, inermi ; coxa inermis ; un. guis parum curvatus, dente valido, acuto armatus.

Lamina cephalica fere æque longa ac lata, glabra, lævis, lateribus rotundatis, manifesto divergentibus, margine postico rotundato, laminam præbasalem maximam partem obtegente; lamina basalis quam lamina cephalica duplo brevior, bis vel ter latior quam longior (tere $5: 2$ ), lamina præbasali in lateribus paulum libera.

Antennæ longiusculæ, articulis prioribus præter primum longis, articulo ultimo articulis duobus antecedentibus conjunctis multo breviore.

Laminæ dorsales læviusculæ, præscutis anterioribus breviusculis vel brevibus, mediis et posterioribus longiusculis.

Spiracula rotunda, anteriora permagna vel magna, per paria sensim magnitudine decrescentia; media et posteriora mediocria.

Laminæ ventralis præter primam et ultimam foveis septenis porosis,

PRoc. AMer. PHILOS. SOc. XXIII. 122. 2C. PRINTEd JANUARY 21, 1886. 
quarum singula rotunda in medium senæque in binas series laterales digestæ, exaratæ.

Pedes paris primi ceteris manifesto breviores et tenuiores; priores per paria sensim longitudine crescentes.

Pleuræ posticæ manifesto inflatæ, glabræ, poris fere tricenis parvis et magnis, subseriatis instructæ; lamina ultima ventralis angusta, lateribus subrectis, multum convergentibus.

Pedes anales pedibus paris anterioris manifesto longiores, paulo tenuiores, ungue parvo armati. .

Pedes leminæ pp. 75 . Long. $47 \mathrm{~mm}$. Lat. $1.7 \mathrm{~mm}$.

A specimen, which was said to be a type of Dr. Wood, was labeled "Strigamia bidens Wood."

Hab. The locality was not more distinct than "N. A. Loc.?"

\section{Scolioplanes ? longicornis, n. sp.}

Sat gracilis, ante valde post manifesto angustatus; fulvus, antennis pedibusque flavis; subglaber, pedibus pilis longioribus sparse vestitis.

Pedes prensorii subglabri, flexi marginem frontalem fere attingentes; sternum subcordiforme, sesqui latius quam longius, coxa fere duplo longius, margine antico in medio alte sinuato; coxa inermis; unguis longus, tenuis, curvatus, dente sat magno armatus.

Lamina cephalica multo longior quam latior (11:8), glabra, lævis, lateribus rotundatis, manifesto convergentibus, margine postico marginem anticum laminæ præbasalis obtegente ; lamina basalis quam lamina cephalica bis vel ter brevior ( $2: 5)$, plus duplo latior quam longior $(9: 4)$, la. mina præbasali magnam partem libera.

Antennæ ad basin fere contiguæ, longæ vel perlongæ, filiformes, articlilis prioribus præter primum perlongis, articulo ultimo articulos duos an tecedentes conjunctos longitudine subæquante.

Laminæ dorsales læviusculæ, præscutis anterioribus breviusculis, mediis et posterioribus longiusculis.

Spiracula rotunda, magna vel mediocria, anteriora paulo majora, per paria sensim magnitudine decrescentia.

Laminæ ventrales sulcatæ, foveis binis exaratæ, sulcis foveisque post sensim obsoletioribus.

Pedes paris primi ceteris vix breviores et tenuiores, anteriores posterioribus paulo crassiores, vix breviores.

Pleuræ posticæ parum inflatæ, subglabræ, poris vicenis magnis, biseriatis instructæ; lamina ultima ventralis minus lata, lateribus subrectis, manifesto convergentibus.

Pedes anales pedibus paris anterioris multo longiores, vix crassiores, ungue magno armati.

Pedes feminæ pp. 107. Long. $65 \mathrm{~mm}$. Lat. $1.2 \mathrm{~mm}$.

Perhaps, or rather probably, this species ought to constitute a 
new genus, but solely I have had for investigation one single specimen, and therefore I have not been able to put the animal and particularly the parts of the mouth to the necessary microscopi cal examination.

\section{Hab. Also the species was labeled "No locality."}

\section{Gen. Himantarium.}

Himantarium (Koch) Meinert, Myriap. Mus. Haun. i. Geophil., p. 21.

Corpus depressum vel subdepressum, lincare vel ante et post levissime angustatum.

Lamina cephalica trophos obtegens; lamina cephalica discreta aut coalita; lamina basalis latissima, transversalis, lateribus post convergentibus vel subparallelis, lamina præbasalis evanida.

Antennæ curtæ, crassæ, attenuatæ.

Labrum liberum, integrum, dentatum.

Labii sternum integrum; processus parvi ; palpi integri vel biarticulati, extrorsum dente magno armati.

Palporum maxillarium unguis minor.

Mandibulæ ante laminis pectinatis pluribus atque lamella dentata in. structæ.

Metameri quarti sternum integrum, lineis chitineis duabus fultum ; pro. sternum haud prominens, obtectum; pedes prensorii ungue inermi.

Scutella spiraculifera parva, præscutello duplo vel pluries minora, pos. scutello parvo discreto; scutella atque præscutella media et interna manifesta.

Laminæ dorsales obsolete bisulcatæ, subglabræ vel scabrosæ ; præscuta breviuscula vel longiuscula.

Pori ventrales in omnibus fere vel in pluribus laminis in aream definitam coarctati.

Pori pleurales sæpissime permulti, interdum pauciores, obtecti vel nulli; pleuræ inflatæ, interdum coxiformes.

Pori anales nulli.

Pedes anales inermes, sexarticulati ; feminæ graciles, subfliformes, subnudi, maris paulo crassiores, breviter hirsuti.

Lamina ultima ventralis plus vel minus triangula, præscutis evanidis vel discretis. Palpi genitales maris manifesto biarticulati.

Lamina ultima dorsalis lævis, simplex.

Lamina frontalis coalita.

1. Himantarium insigne, n. sp.

Robustum, ante et post manifesto angustatum; olivaceum vel lurilum; glabrum.

Pedes prensorii glabri, flexi marginem frontalem procul attingentes; 
sternum plus duplo latius quam longius (7:3), coxa sesqui longius, margine antico in medio late sinuato, inermi ; coxa inermis; unguis valde curvatus, inermis.

Lamina cephalica subsemicircularis, vix sesqui latior quam longior (10:7), glabra, læviuscula, margine postico latissime rotundato, marginem anticum medium laminæ basalis obtegente ; lamina basalis quam lamina cephalica plus quater brevior, quater vel quinquies latior quam longior (fere $9: 2$ ).

Antennæ breves, ad basin contigıæ, incrassatæ, manifesto attenuatæ, articulis præter ultimum transversalibus, articulo ultimo articulis duobus antecedentibus conjunctis multo longiore $(4: 3)$.

Laminæ dorsales læviusculæ, foveis binis lateralibus, obsoletis exaratæ, præscutis longiusculis.

Spiracula subovalia, paulum obliqua, mediocria, anteriora posterioribus paulo majora.

Laminæ ventrales præter primam et ultimam pone medium area transversali, porosa instructæ.

Pedes paris primi ceteris paulo breviores atque tenuiores, anteriores et posteriores subæquales.

Pleuræ posticæ coxiformes, non inflatæ, integræ; lamina ultima ventralis parva, transversalis, lateribus subrectis, paulum convergentibus, margine postico angulatim sinuato.

Pedes anales pedibus paris anterioris paulo breviores, manifesto tenui. ores, inermes.

Pedes feminæ pp. 7\%. Long. $105 \mathrm{~mm}$. Lat. $4 \mathrm{~mm}$.

Hab. Koolloo, Rev. Mr. Carleton.

\section{Himantarium Indicum, n. sp.}

Sat robustum, ante multum, post paulum angustatum; fulvum vel flavum, glabrum, pedibus pilis brevibus sparsissime vestitis.

Pedes prensorii glabri, flexi marginem frontalem spatio magno non attingentes ; sternum duplo latius quam longius, coxa duplo longius, margine antico in medio late sinuato, inermi ; coxa inermis; unguis valde curvatus, inermis.

Lamina cephalica æque longa ac lata, glabra, læviuscula, lateribus rotundatis, manifesto divergentibus, margine postico vix rotundato marginem anticum laminæ basalis obtegente; lamina basalis quam lamina cephalica plus quater brevior, quater vel quinquies latior quam longior.

Antennæ breves vel perbreves, ad basin distantes, crassæ attenuatæ, articulis præter ultimum transversalibus, articulo ultimo articulis duobus antecedentibus conjunctis manifesto longiore.

Laminæ dorsales læviusculæ vel obsolete rugulosæ, præscutis anterioribus brevibus vel breviusculis, mediis et posterioribus longis vel longius. culis.

Spiracula rotunda anteriora magna, per paria sensim magnitudine paulum decrescentia, media et posteriora parva. 
Laminæ ventrales præter primam et ultimam impressione lineari, transversali, porosa notatæ.

Pedes paris primi ceteris paulo breviores atque tenuiores, anteriores posterioribus paulo crassiores.

Pleuræ posticæ coxiformes, pilis brevissimis sparse vestitæ, integræ; lamina ultima ventralis sat parva, lateribus rectis, parum convergentibus.

Pedes anales pedibus paris anterioris multo longiores, aut vix (feminæ) aut valde (maris) crassiores, articulo ultimo quam penultimo paulo longi. ore, inermes.

Pedes feminæ pp. 67 ; maris 67. Long. feminæ $45 \mathrm{~mm}$; maris $53 \mathrm{~mm}$. Lat. maris $2.2 \mathrm{~mm}$.

Hab. Koolloo, Rev. Mr. Carleton.

\section{Himantarium teniopse.}

Strigamia tceniopsis Wood, Journ. Acad. Nat. Soc. Philad., new ser., v, p. 48.

Trans. Amer. Philos. Soc. xiii, p. 185.

Minus gracile, ante et post paulum angustatum; fulvum vel flavum; glabrum.

Pedes prensorii glabri, flexi marginem frontalem fere attingentes ; sternum fere duplo latius qụam longius, coxa fere sesqui longius, margine antico in medio late sinuato, inermi; coxa inermis; unguis curvatus, inermis.

Lamina cephalica multo latior quam longior (fere $4: 3$ ), glabra, læviuscula, margine postico subrecto, marginem anticum laminæ basalis obte. gente ; lamina basalis quam lamina cephalica plus ter brevior (fere $3: 10$ ), quater latior quam longior.

Antennæ lengiusculæ, ad basin distantes, paulum incrassatæ, manifesto attenuatæ, articulis prioribus præter primum longiuscul.s, articulo ultimo articulis duobus antecedentibus conjunctis manifesto breviore.

Laminæ dorsales læviusculæ, præscutis anterioribus breviusculis, mediis et posterioribus longiusculis.

Spiracula subovalia, perpendicularia, anteriora magna, per paria sensim magnitudine paulum decrescentia, media et posteriora minuta.

Laminæ ventrales anteriores area majore, subovali, transversali, porosa, mediæe et posteriores area minore vel parva, rotundata, porosa pone medium exaratæ.

Pedes paris primi ceteris paulo vel vix breviores, anteriores posterioribus manifesto crassiores, paulo breviores.

Pleuræ posticæ parum inflatæ, glabræ, integræ; lamina ultima ventralis mediocris, lateribus rotundatis, multum convergentibus.

Pedes anales pedibus paris anterioris vix longiores, manifesto tenuiores, inermes.

Pedes feminæ pp. 143. Long. $130 \mathrm{~mm}$. Lat. $2.4 \mathrm{~mm}$.

\section{Hab. San Diego, Cal.}




\section{Himantarium laticeps.}

Strigama laticeps Wood, Journ. Acad. Nat. Sc. Philad., new ser., v, p. 49.

Trans. Amer. Philos. Soc. xiii, p. 186.

Gracile, ante et post leviter angustatum, ochraceum, glabrum.

Pedes prensorii glabri, flexi marginem frontalem fere attingentes; sternum oblingulatum, plus duplo latius quam longius $(9: 4)$, coxa vix duplo longius (fere $9: 5$ ), margine antico in medio sat alte sinuato, inermi ; coxa inermis ; unguis parum curvatus, inermis.

Lamina cephalica multo latior quam longior (4:3), glabra, lævis, subpentagona, partem anteriorem mediam laminæ basalis obtegens; lamina basalis, quoad liberam, quam lamina cephalica quater brevior, quinquies latior quam longior.

Laminæ dorsales obsolete bisulcatæ, area media paulum depressa, præscutis breviusculis vel longiusculis.

Spiracula rotunda, anteriora magna ; media et posteriora parva.

Laminæ ventrales præter primam et ultimam area angusta, transversali, porosa in medio vel post sensim marginem posticum proprius exaratæ.

Pedes paris primi ceteris manifesto breviores, anteriores posterioribus manifesto crassiores.

Pleuræ posticæ parum inflatæ, glabræ, foveis ternis magnis, semiobtectis, porosis instructæ; lamina ultima ventralis sat lata, post angulatim sinuata, profunde sulcata, lateribus rectis, valde convergentibus.

Pedes anales pedibus paris anterioris paulo breviores, valde crassiores, inermes.

Pedes maris pp. 81 . Long. $76 \mathrm{~mm}$. Lat. $1.4 \mathrm{~mm}$.

Hab. Texas, Chas. Stolley (the type of Mr. Wood).

\section{Gen. Orphnaeus.}

Orphnceus Meinert, Myriap. Mus. Haun. i, Geophil., p. 17.

Corpus subdepressum, ante et post minus angustatum.

Lamina cephalica trophos plus vel minus obtegens; lamina frontalis coalita ; lamina basalis latior, lateribus post paulum divergentibus ; lamina præbasalis evanida.

Antennæ subteretes, curtæ, paulum attenuatæ.

Labrum liberum, integrum, dense dentatum.

Labii sternum integrum; processus breves; palpi integri, extrorsum processis binis membranaceis instructæ.

Palporum maxillarium unguis sat magnus.

Mandibulæ ante laminis pectinatis quaternis vel quinis instructæ.

Metameri quarti sternum integrum, transversale, simplex; prosternum haud prominens, obtectum; pedes prensorii ungue inermi.

Scutella spiraculifera magna, fere magnitudinis prrescutelli, postscutello majore discreto ; scutella atque præscutella interna evanida. 
Laminæ dorsales leviter vel levissime scabrosæ, bifoveolatæ; præscuta majora.

- Pori ventrales in plagas quaternas digesti.

Pori pleurales nulli.

Pori anales nulli.

Pedes anales inermes, pseudo-septemarticulati, pleuris coxas simulantibus, hirsuti ; feminæ sat graciles, attenuati, maris aliquanto crassiores.

Lamina ultima ventralis lata, obtusa, præscutis discretis. Palpi genitales maris manifesto biarticulati.

\section{OrphNaUs hividus.}

Orphnceus lividus Meinert, Myriap. Mus. Haun. i. Geophil., p. 19.

Minus robustus, ante et post paulum angustatus ; ochraceus vel lividus, vitta media, duplice, latiore, fusca in dorso plus vel minus manifesto notatus.

Pedes prensorii glabri, flexi marginem frontalem spatio magno non attingentes; sternum plus duplo latius quam longius (fere $11: 5$ ), coxa plus duplo longius $(7: 3)$, margine antico in medio late sinuato, inermi ; coxa inermis ; unguis curvatus, inermis.

Lamina cephalica multo latior quam longior (fere 5:4), glabra, lævius cula, lateribus rotundatis, manifesto divergentibus, margine postico subrecto, marginem anticum laminæ basalis obtegente; lamina basalis quam lamina cephalica plus duplo brevior (fere $3: 7$ ), vix ter latior quam longior (fere $11: 4$ ).

Antennæ breves vel perbreves, ad basin distantes, crassæ, attenuatæ, articulis præter ultimum transversalibus, articulo ultimo articulis duobus antecedentibus conjunctis paulo breviore.

Laminæ dorsales leviter scabrosæ foveis ternis, media multo majore et obsoletiore, plus vel minus manifesto exaratæ, præscutis brevibus.

Spiracula ovalia, obliqua, anteriora magna, per paria sensim magnitudine paulum decrescentia ; media et posteriora parva vel minuta.

Laminæ ventrales præter primam et sæpe ultimam fovea media vel foveis ternis in seriem transversalem digestis notatæ, poris in plagas quaternas magnas dispositis.

Pedes paris primi ceteris vix breviores atque tenuiores, anteriores et posteriores subæquales.

Pleuræ posticæ vix inflatæ, glabræ, integræ; lamina ultima ventralis parva, transversalis, lateribus rectis, valde convergentibus.

Pedes anales pedibus paris anterioris paulo breviores, vix (feminæ) aut aliquanto (maris) crassiores, inermes.

Pedes feminæ pp. 71-79; maris 71. Long. feminæ $85 \mathrm{~mm}$.; maris 50 mm. Lat. feminæ $2.75 \mathrm{~mm}$.

Hab. Sandwich islands, Society islands, J. M. Barnard; Ascension islands, South sea; Zanzibar, Mr. Cooke. 


\section{Orphnaus Brasiliensis.}

Orphnceus Brasiliensis Meinert, Myriap. Mus. Haun. i. Geophil., p 20.

Minus vel sat robustus, ante multum post paulum angustatus, ochraceus vel pallide lividus, capite cum trophis laminaque basali dorsalique ultima fulvo vel brunneo, antennis fulvis, maculis fuscis, in series plures digestis, notatus ; subglaber.

Pedes prensorii glabri, flexi marginem frontalem magno spatio non attingentes; sternum ter latius quam longius, coxa sesqui longius, margine antico in medio leviter sinuato, inermi ; coxa inermis ; unguis curvatus, inermis.

Lamina cephalica manifesto latior quam longior, glabra, læviuscula, lateribus rotundatis, paulum divergentibus, margine postico subrecto, marginem anticum laminæ basalis obtegente ; lamina basalis quam lamina cephalica plus duplo brevior $(9: 20)$, ter latior quam longior.

Antennæ breves, ad basin distantes, crassæ, attenuatæ, articulis præter ultimum transversalibus, articulo ultimo articulis duobus antecedentibus conjunctis paulo longiore.

Laminæ dorsales bi- vel trisulcatæ, sulco medio latiore, obsoletiore. foveis binis lateralibus notatæ.

Spiracula ovalia, anteriora obliqua, magna, per paria sensim magnitudine decrescentia; media et posteriora prona, parva.

Laminæ ventrales fovea vel area media, post sensim paulo majore atque obsoletiore impressæ, lateribus porosis.

Pedes paris primi ceteris manifesto breviores, anteriores posterioribus manifesto crassiores, vix breviores, medii paulo longiores.

Pleuræ posticæ vix inflatæ, glabræ, integræ; lamina ultima ventralis sat parva, lateribus subrectis, valde convergentibus.

Pedes anales pedibus paris anterioris paulo breviores, vix (feminæ) aut aliquanto (maris) crassiores, inermes.

Pedes feminæ pp. 75-85; maris 67. Long. feminæ $86 \mathrm{~mm}$. ; maris 47 mm. Lat. feminæ $2.1 \mathrm{~mm}$.

Hab. Rio de Janeiro, Thayer Exped.; Panama; Poloon, Occidental Dept., Nicaragua, Mr. McNiel.

\section{Gen. Notiphilides.}

Notiphilides Latzel, Myriap. oesterr. ung. Mon., p. 20.

Corpus depressum, ante et post angustatum.

Lamina cephalica trophos non obtegens; lamina frontalis coalita ; lamina basalis lata, lateribus post paulum divergentibus ; lamina præbasalis evanida.

Antennæ subdepressæ, curtæ, parum attenuatæ.

Labrum coalitum integrum, margine antico interne dense, externe sparsim dentato.

Labii sternum integrum; processus breves, perlati, subconici; palpi lati, integri, extrorsum processibus binis longis instructi. 
Palporum maxillarium unguis in marginibus interioribus in dentes plures incisus.

Mandibulæ ante laminis pectinatis quaternis instructæ.

Metameri quarti sternum integrum, transversale, simplex ; prosternum haud prominens, obtectum; pedes prensorii coxa inermi.

Scutella spiraculifera magna, præscutello paulo minora, postscutello majore discreto; scutella et præscutella interna manifesta.

Laminæ dorsales bisulcatæ; præscuta brevia.

Pori ventrales minimi, in marginem anticum et posticum digesti, inconspicui.

Pori pleuralis nulli.

Pori anales nulli.

Pedes anales inermes, pseudo-sexarticulati, pleuris coxas simulantibus, feminæ subgraciles, parum attenuati, subnudi, maris parum incrassati atque attenuati, subnudi.

Lamina ultima ventralis transversalis, præscutis nulles discretis. Palpi genitales maris manifesto biarticulati.

\section{Notiphilides Maximiliani.}

Notiphilus Maximiliani Humbert et Saussure, Rev. et Mag. Zool., 2 sér., xxii, p. 205.

Saussure et Humbert, Etud. s. Myriap., p. 141, tab. vi, figs. $22,22 \mathrm{~d}, 22 \mathrm{v}$.

Robustus, ante et post manifesto angustatus; brunneo-olivaceus, glaber.

Pedes prensorii glabri, flexi marginem frontalem procul attingentes; sternum ter latius quam longius, coxa duplo longius, margine antico in medio late sinuato, inermi ; coxa inermis ; unguis inermis.

Lamina cephalica multo latior quam longior, lævis, subovalis, margine postico a lamina basali obtecto ; lamina basalis quater latior quam longior.

Antennæ breviusculæ vel breves, attenuatæ, articulis præter ultimum transversalibus, articulo ultimo articulos duos antecedentes conjunctos longitudine subæquante.

Laminæ dorsales manifesto scrobiculatæ, præscutis brevissimis.

Spiracula subovalia, obliqua, anteriora majora, per paria sensim magnitudine decrescentia; media et posteriora minora.

Laminæ ventrales præter sulcos binos lateralibus maximam partem porosæ, impressione media, angusta, simplice notatæ.

Pedes paris primi ceteris multo breviores, paulo tenuiores, anteriores posterioribus subæquales.

Pleuræ posticæ coxiformes, integræ; lamina ultima ventralis parva, transversalis, lateribus subrectis, multum convergentibus.

Pedes anales pedibus paris anterioris manifesto breviores, multo crassiores, inermes.

Pedes feminæ pp. 97 ; maris 85 . Long. feminæ $90 \mathrm{~mm}$. ; maris 55. Lat feminæ $3.7 \mathrm{~mm}$.

\section{Hab. Guatemala, v. Patten.}

PRoc. AMEr. Philos. soc. XXIII. 122. 2D. PRINTEd JANUARY 21, 1886. 


\section{$2 \mathrm{BHL}$ Biodiversity Heritage Library}

Meinert, Fr. 1886. "Myriapoda Musei Cantabrigiensis. Part I. Chilopoda." Proceedings of the American Philosophical Society held at Philadelphia for promoting useful knowledge 23, 161-233. https://doi.org/10.5962/bhl.part.26797.

View This Item Online: https://www.biodiversitylibrary.org/item/31070 DOI: https://doi.org/10.5962/bhl.part.26797

Permalink: https://www.biodiversitylibrary.org/partpdf/26797

\section{Holding Institution}

Harvard University, Museum of Comparative Zoology, Ernst Mayr Library

\section{Sponsored by}

Harvard University, Museum of Comparative Zoology, Ernst Mayr Library

\section{Copyright \& Reuse}

Copyright Status: NOT_IN_COPYRIGHT

This document was created from content at the Biodiversity Heritage Library, the world's largest open access digital library for biodiversity literature and archives. Visit BHL at https://www.biodiversitylibrary.org. 